This document is published in:

Spanish Economic Review, 2007, vol. 9, no 1, p. 1-38

DOI: http://dx.doi.org/10.1007/s10108-006-9008-9

(C) Springer-Verlag 2006 


\title{
Economic inequality in Spain: the european community household panel dataset
}

\author{
Santiago Budría · Javier Díaz-Giménez
}

\begin{abstract}
This article uses data from the 1998 European Community Household Panel to study economic inequality in Spain. It reports data on the Spanish distributions of income, labor income, and capital income, and on related features of inequality, such as age, employment status, educational attainment, and marital status. It also reports data on the income mobility of Spanish households, and data on income inequality in other European countries and in the US. We find that income, earnings, and, especially, capital income are very unequally distributed in Spain and that economic inequality in Spain is well above the European average.
\end{abstract}

Keywords Inequality - Income distribution - Labor earnings distribution · Capital income distribution

JEL Classification $\quad \mathrm{D} 310 \cdot \mathrm{J} 310$

\section{Introduction}

Purpose. The purpose of this article is to report facts on the distributions of income, earnings, capital income, and transfers in Spain. Even though our understanding of inequality has advanced significantly in the last few years, there is

\footnotetext{
S. Budría

Universidad de Madeira and CEEAplA, Funchal, Portugal

e-mail: sbudria@uma.pt

J. Díaz-Giménez $(\bowtie)$

Universidad Carlos III de Madrid and CAERP, Madrid, Spain

e-mail: kueli@eco.uc3m.es
} 
still no established theory to help us organize the data. Therefore, we have attempted to report the data in a format that satisfies the following two criteria: it should be possible to analyze the data with any given theory of inequality, and it should be possible to use the data to test the implications of any given theory of inequality. Thus, the pages that follow are an attempt to highlight the main features of the data in a coherent and summarized fashion. This article, however, is not an attempt to carry out a thorough statistical analysis of the data.

The Dataset. The data reported in this article have been obtained from the 1998 and the 1994 waves of the Spanish survey of the European Community Household Panel (henceforth, Europanel) in which the households were asked to report their economic data of 1993 and 1997, respectively. In the section "the dataset" below we discuss some of the main features of this dataset.

Inequality is multidimensional. The complexity of the problem of inequality has forced us to concentrate on the study of some of its dimensions and to ignore many others. Specifically, the dimensions of inequality which we describe in this article are the following:

Income, earnings, and capital income inequality. Together with wealth, income and earnings inequality are the three dimensions of inequality that are most frequently studied. Since the Europanel does not include data on wealth, in this article we study the distributional features of income and its main components: labor earnings, capital income and transfers. Labor earnings is the sum of net labor income from both paid employment and self-employment. Capital income is the sum of net capital and property income. Transfers are the sum of both private and public transfers. In the section "Definitions of variables" below we discuss the definitions of these variables in greater detail.

To document some of income, earnings, and capital income inequality facts we rank the 1998 Spanish Europanel households along each one of these three dimensions and we study the resulting distributions. We find that capital income, with a Gini index of 0.95 , is by far the most concentrated of the three variables; that earnings, with a Gini index of 0.57 , ranks second; and that income, with a Gini index of 0.39 , is the least concentrated of the three. ${ }^{1}$ Furthermore, we find that the correlations between earnings and capital income, on the one hand, and between income and capital income, on the other, which are 0.10 and 0.44 , respectively, are significantly smaller that the correlation between earnings and income, which is 0.84 . In the section "Earnings, income, and capital income inequality" we report these findings.

\footnotetext{
1 The Lorenz curve of a distribution gives us a measure of its relative inequality. Specifically, on the horizontal axis we plot the shares of the population (e.g. the poorest $10 \%$, the next $10 \%$, and so on), and on the vertical axis we plot the shares of the total income, earnings, or capital income earned by that group. Consequently, the Lorenz curve of a variable that is exactly equally distributed is a $45^{\circ}$ line, and as the inequality of a distribution increases, its Lorenz curve becomes increasingly bowed towards the bottom right corner of its graph.

The Gini index of a distribution is twice the area between its Lorenz curve and the diagonal of the unit square. Consequently, the Gini index of a variable that is exactly equally distributed is zero, and the Gini index of a variable which is completely accumulated in only one household is one.
} 
The poor and the rich. Income, earnings, and capital income inequality is essentially about the differences between the poor and the rich. However, the meanings of these two words are somewhat ambiguous. When we talk about the rich, it is not clear whether we are referring to the income-rich, the earnings -rich, or to the capital income-rich, and the same ambiguity applies to the income-poor, the earnings-poor, and the capital income-poor. In the section "The poor and the rich" we describe the income, earnings, and capital income of the households in the tails of the corresponding distributions, and we document the ways in which these three concepts of poor and rich differ.

Age and inequality. Age is one of the main determinants of income, earnings, and capital income inequality. To document this fact, in the section "The age and inequality" we partition the 1998 Spanish Europanel sample into eleven age cohorts, according to the age of the household head and we report some of the main income, earnings, and capital income inequality facts of the different groups in this age partition. ${ }^{2}$ We find that, on average, the households whose heads are between 51 and 55 years old are both the earnings and the income richest; that the households whose heads are between 61 and 65 are the capital income richest; and that, amongst working-age households, those whose head is under 25 are the income and earnings poorest. We also find that, overall, the measures of income, earnings, and capital income inequality within the different age cohorts are similar to those that obtain for the entire sample.

Occupation and inequality. The main occupation of the household heads is another important determinant of inequality. To document this relationship, in the section "Employment status and inequality" we partition the 1998 Spanish Europanel sample into workers (people who are employed by others), the self-employed, retirees, and non-workers (people who do not work but who do not consider themselves to be retired), according to the employment status of the household head. We find that the households headed by workers are, on average, the income and earnings richest; that the self-employed are, by far, the capital income richest; and that the households headed by a non-worker are the income poorest.

Education and inequality. Education increases the market value of people's time. Consequently, it plays a potentially important role in determining economic inequality. To characterize the relationship between education and inequality, in the section "Education and inequality" we partition the 1998 Spanish Europanel sample into college households, secondary education households, primary education households, and no-primary education households according to the education level completed by the household heads. Not surprisingly, we find that income, earnings, and capital income inequality differ significantly between these education groups. More specifically, we find that college graduates are, on average, the income, earnings, and capital income richest, and

\footnotetext{
2 The Europanel questionnaire is sent to a "reference person" in each household. This person is usually the household head but it could be another member of the household. In this article we abuse the language somewhat and we talk about "household head" when we really mean "reference person".
} 
that the households whose head has not completed primary education are, on average, the income, earnings, and capital income poorest. We also find that college graduates have higher capital income to earnings ratios than the other three education groups.

Marital status and inequality. To explore the relationship between marital status and inequality, in the section "Marital status and inequality" we partition the 1998 Spanish Europanel sample into married households, single households with dependents, and single households without dependents, according to the marital status of the household head. The singles are further partitioned by sex. We report the main income, earnings, and capital income inequality facts for these seven marital status groups and we find that, as far as the economic performance of households is concerned, married people are better off. We also find that single females are significantly worse off than single males.

Income mobility. Since people move up and down the economic scale, in the section "Income mobility" we report some facts about the income mobility of Spanish households. Not surprisingly, we find that the households in the middle quintiles are more mobile than those in either the lowest or the top quintiles. ${ }^{3}$ We also find that the income-rich are somewhat more mobile than the income-poor.

International comparisons. Finally, in the section "International comparisons", we take advantage of the fact that the Europanel methodology is very similar in all the European Union countries to carry out some international comparisons. For completeness sake we also report some inequality data for the US economy which we have constructed from the 1998 US Survey of Consumer Finances. Most of the data suggest that economic inequality in Spain is well above the European average.

\section{The dataset}

The Europanel is a standardized survey that is carried out in the European Union. Its period is yearly and its purpose is to obtain "comparable information across the member states on income, work and employment, poverty and social exclusion, housing, health, and many other diverse social indicators concerning the living conditions of households and persons" (Eurostat 1996).

The Europanel defines a household as a group of people that share the same dwelling and have common living arrangements. The first year in which the Spanish data was collected was 1994. The original Spanish sample was made up of 7,206 households. The survey then follows the sample people, and it includes the children born to the initial sample women and the new households formed

\footnotetext{
3 Strictly speaking, the $i$ th quintile of a distribution $F$ is the value in the support of that distribution that solves the equation $F(x)=0.2 i$. In this article, we discuss the shares of total income, earnings, and capital income earned by various groups: the poorest $20 \%$, the next $20 \%$ and so on, however, we abuse the language and we call these groups quintiles. We abuse the language likewise with the other Lorenz curve groups.
} 
by members of the original ones. In this and in other aspects the Europanel resembles the University of Michigan's Panel Study of Income Dynamics (PSID).

By 1998, the Spanish sample contained only 5,427 households. This significant reduction of the sample size raises the issue of the representativity of the 1998 sample. We discuss some of the technical issues arising from this reduction of the sample size in the Appendix. ${ }^{4}$

\section{Definitions of variables}

The definitions of income, labor earnings, capital income, and transfers that we use in this article are the following:

- Labor earnings: we define labor earnings as the sum of net labor income both from paid employment and from self-employment.

- Capital income: we define capital income is the sum of net capital income and net property income.

- Transfers: we define transfers as are the sum of private and public transfers. Private transfers include inter-vivos transfers and bequests. Public transfers include retirement pensions and old-age benefits, unemployment compensation and other work-related transfers, survivors benefits, illness and disability benefits, family benefits, education grants, social aid, housing subsidies and other public transfers.

- Income: we define income as the sum of labor earnings, capital income, and transfers.

Once we have collected the data on these variables, we construct three different rankings of the sample households using their income, earnings, and capital income as the ranking criterion. In Tables 1,2 , and 3 we report summaries of the main inequality facts of the resulting distributions. Note that in Table 2 the poorest group is the bottom $30 \%$ of the distribution because $30.2 \%$ of the sample households report zero earnings. Likewise, the poorest group in Table 3 is the bottom $40 \%$. We discuss the main inequality facts that arise from these partitions in the sections "Earnings, income, and capital income inequality" and "The poor and the rich" below.

\section{Earnings, income, and capital income inequality}

The 1998 wave of the Spanish survey of the Europanel unambiguously shows that income, earnings, and capital income are unequally distributed across the households in the sample. The values of the concentration statistics that we have computed are large, and the histograms of the three distributions are skewed to the right; that is, they present very short and fat lower tails and very thin and long upper tails (see Fig. 1).

${ }^{4}$ For an excellent technical discussion on the methods used to deal with the problems created by attrition and non-response in the Europanel, see Peracchi (2002). 
The concentration statistics that we report in Table 4 below rank income as the least unequally distributed of the three variables, and capital income, by far, as the most unequally distributed. As we have already mentioned, in Tables 1 , 2 , and 3 , we report a detailed set of statistics that describe the income, earnings, and capital income partitions. In the subsections below we use some of those statistics to describe the main income, earnings, and capital income inequality facts.

Ranges and shapes of the distributions

Panels 1, 2 and 3 of Fig. 1 contain the histograms of the distributions of income, earnings, and capital income, and Panel 4 contains the distribution of earnings when we exclude the households headed by a retiree from the sample. In these figures, the levels have been normalized by the mean, and the last intervals of the distributions depicted in Panels 2 and 3 represent the frequencies of households with more than 10 times the corresponding averages.

Income ranges from zero to 9.8 times the sample average of 16,140 1997 euros. ${ }^{5}$ Earnings range from zero to 10.3 times the sample average of 11,094 euros and capital income ranges from zero to a startling 120.8 times the sample average of 736 euros. This extremely large normalized range of the capital income distribution is due to the facts that $40.6 \%$ of the households report zero capital income, that capital income accounts for a small fraction of average income, and that maximum capital income is fairly large. Specifically, while capital income accounts for only $4.6 \%$ of average income, it accounts for $54.9 \%$ of maximum income. ${ }^{6}$

As Fig. 1 illustrates, all three distributions are significantly skewed to the right. The top-coding used to draw these figures hides the large dispersion of capital income: while approximately $79 \%$ of the sample households report less than average capital income (736 euros), three percent of the households report more than ten times that value.

\section{Concentration}

To describe the concentration of income, earnings, and capital income, in Fig. 2 we plot the Lorenz curves of these three variables. In Table 4 we report the Gini indexes, the coefficients of variation and the ratios of the shares earned or owned by the top percentile and the bottom $60 \%$ of the distributions of income, earnings, and capital income. We have chosen to report this last statistic because the bottom $60 \%$ is the poorest group that earns a strictly positive share of all three variables.

\footnotetext{
5 The unit of account used in the 1998 Spanish Europanel was 1997 Spanish Pesetas (PTE). We have transformed this units into euros using the entry exchange rate $166.386 \mathrm{PTE}=1$ euro. We call this units 1997 euros or, for the sake of brevity, simply, euros.

${ }^{6}$ Earnings and transfers account for $68.7 \%$ and $26.7 \%$ of average income, respectively.
} 
Table 1 Spanish households ranked by income

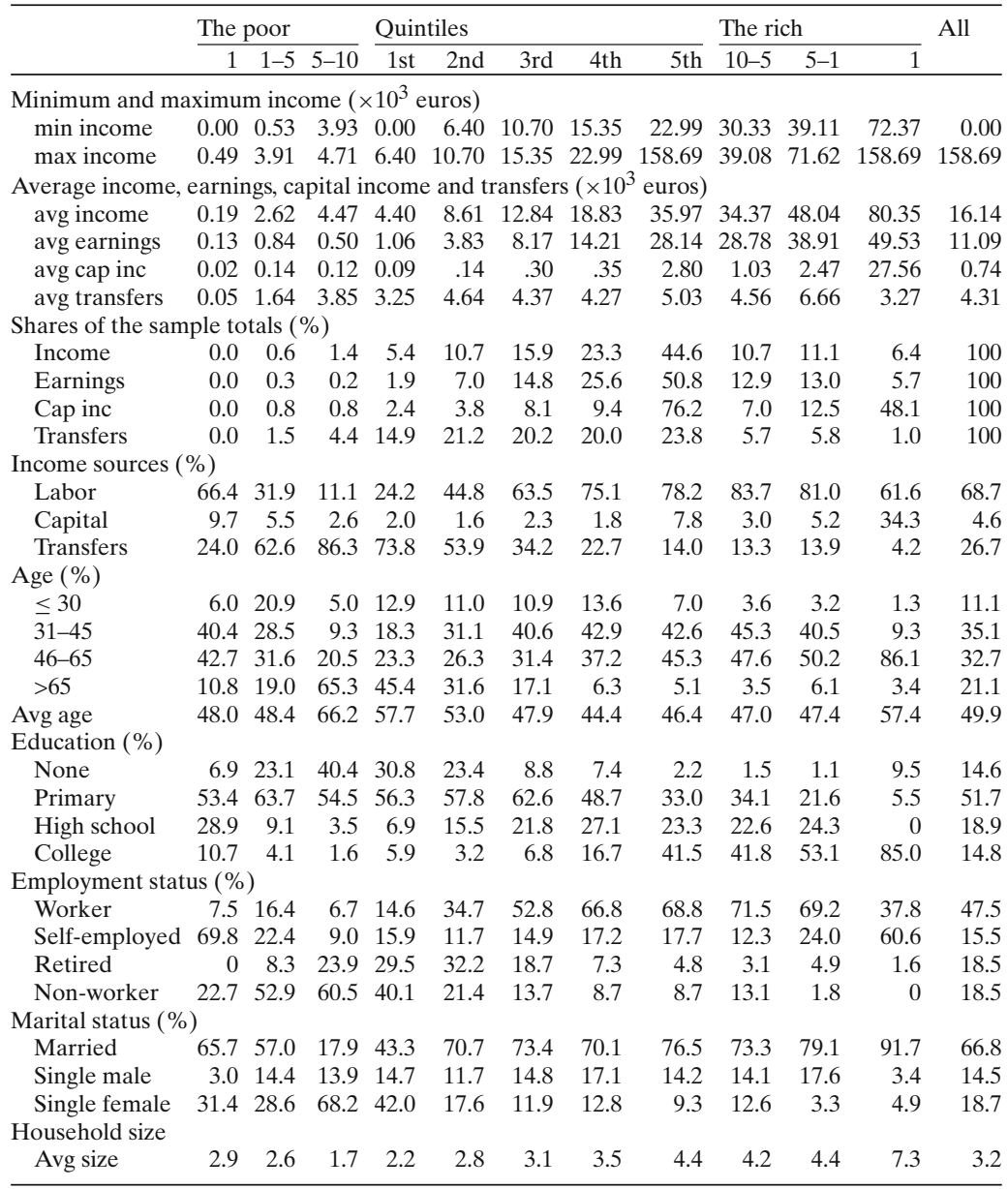

Source: Spanish Survey of the 1998 European Community Household Panel

Figure 2 shows that capital income is by far the most unequally distributed of the three variables and that earnings is more unequally distributed than income. This is reflected by the facts that the Lorenz curve of capital income lies significantly below the Lorenz curves of both earnings and income, and that the Lorenz curve of earnings lies below the Lorenz curve of income. The fact that the Lorenz curves do not intersect simplifies the comparisons. As we discuss below, income is more equally distributed than earnings partly as a result of the equalizing effect of income transfers. 
Table 2 Spanish households ranked by earnings

\begin{tabular}{|c|c|c|c|c|c|c|c|c|c|}
\hline & \multicolumn{2}{|c|}{ The poor } & \multicolumn{3}{|c|}{ Quintiles } & \multicolumn{3}{|c|}{ The rich } & \multirow[t]{2}{*}{ All } \\
\hline & $\overline{0-30}$ & $30-40$ & $\overline{40-60}$ & $60-80$ & $80-100$ & $\overline{10-5}$ & $5-1$ & 1 & \\
\hline \multicolumn{10}{|c|}{ Minimum and maximum earnings $\left(\times 10^{3}\right.$ euros $)$} \\
\hline Min earnings & 0 & 0.11 & 5.44 & 11.78 & 19.21 & 26.89 & 33.75 & 52.51 & \\
\hline Max earnings & 0.11 & 5.43 & 11.78 & 19.20 & 113.77 & 33.69 & 52.07 & 113.77 & 113.77 \\
\hline \multicolumn{10}{|c|}{ Average income, earnings, capital income and transfers $\left(\times 10^{3}\right.$ euros $)$} \\
\hline Avg income & 8.73 & 7.27 & 12.06 & 17.86 & 34.01 & 31.59 & 42.98 & 73.99 & 16.14 \\
\hline Avg earnings & 0.00 & 2.75 & 8.62 & 15.12 & 30.30 & 29.4 & 40.16 & 70.35 & 11.09 \\
\hline Avg cap inc & 0.53 & 0.26 & 0.25 & 0.32 & 2.18 & 1.30 & 1.27 & 1.64 & 0.74 \\
\hline Avg transfers & 8.20 & 4.26 & 3.18 & 2.41 & 1.52 & 0.88 & 1.55 & 2.00 & 4.31 \\
\hline \multicolumn{10}{|c|}{ Shares of the sample totals (\%) } \\
\hline Income & 16.2 & 4.5 & 14.9 & 22.1 & 42.1 & 9.6 & 10.8 & 4.8 & 100 \\
\hline Earnings & 0 & 2.5 & 15.6 & 27.3 & 54.8 & 13.0 & 14.7 & 6.6 & 100 \\
\hline Cap inc & 1.4 & 0.2 & 0.5 & 0.6 & 3.9 & 8.6 & 7.0 & 2.3 & 100 \\
\hline Transfers & 57.1 & 9.9 & 14.8 & 11.2 & 7.0 & 1.0 & 1.5 & 0.5 & 100 \\
\hline \multicolumn{10}{|c|}{ Income sources $(\%)$} \\
\hline Labor & 0 & 37.8 & 71.6 & 84.7 & 89.2 & 93.1 & 93.5 & 95.1 & 68.7 \\
\hline Capital & 6.1 & 3.6 & 2.1 & 1.8 & 6.4 & 4.1 & 2.9 & 2.2 & 4.6 \\
\hline Transfers & 93.9 & 58.6 & 26.4 & 13.5 & 4.5 & 2.8 & 3.6 & 2.7 & 26.7 \\
\hline \multicolumn{10}{|l|}{ Age $(\%)$} \\
\hline$\leq 30$ & 4.4 & 25.4 & 17.6 & 12.4 & 6.0 & 6.3 & 2.8 & 1.6 & 11.1 \\
\hline $31-45$ & 6.9 & 38.5 & 51.1 & 49.1 & 45.9 & 49.5 & 37.2 & 28.3 & 35.1 \\
\hline $46-65$ & 21.0 & 32.2 & 30.5 & 38.0 & 47.5 & 43.4 & 59.0 & 66.3 & 32.7 \\
\hline$>65$ & 67.7 & 3.9 & 0.9 & 0.5 & 0.6 & 0.8 & 1.0 & 3.9 & 21.1 \\
\hline Avg age & 66.8 & 41.1 & 40.8 & 42.4 & 45.3 & 44.8 & 48.1 & 49.6 & 49.9 \\
\hline \multicolumn{10}{|l|}{ Education (\%) } \\
\hline No-primary & 33.5 & 12.4 & 7.9 & 6.2 & 2.1 & 2.2 & 1.0 & 10.3 & 14.6 \\
\hline Primary & 53.1 & 63.6 & 59.0 & 52.8 & 35.3 & 32.6 & 23.6 & 17.2 & 51.7 \\
\hline Secondary & 8.2 & 14.8 & 25.1 & 27.7 & 22.3 & 21.6 & 23.0 & 0 & 18.9 \\
\hline College & 5.3 & 9.2 & 8.0 & 13.3 & 40.2 & 43.6 & 52.4 & 72.4 & 14.8 \\
\hline \multicolumn{10}{|c|}{ Employment status (\%) } \\
\hline Worker & 2.9 & 36.7 & 68.4 & 70.2 & 76.4 & 81.9 & 76.3 & 80.8 & 47.5 \\
\hline Self-employed & 3.0 & 26.4 & 20.3 & 22.9 & 16.5 & 9.9 & 15.7 & 18.0 & 15.5 \\
\hline Retired & 58.6 & 4.1 & 1.5 & 0.7 & 0.4 & 0 & 0.5 & 0 & 18.5 \\
\hline Non-worker & 35.6 & 32.8 & 9.9 & 6.3 & 6.7 & 8.2 & 7.5 & 1.3 & 18.5 \\
\hline \multicolumn{10}{|l|}{ Marital status (\%) } \\
\hline Married & 51.5 & 60.5 & 66.1 & 75.8 & 84.7 & 83.2 & 89.9 & 91.3 & 66.8 \\
\hline Single male & 14.1 & 18.8 & 17.3 & 15.6 & 9.1 & 11.9 & 6.7 & 2.6 & 14.5 \\
\hline Single female & 34.4 & 20.7 & 16.7 & 8.7 & 6.3 & 4.9 & 3.3 & 6.1 & 18.7 \\
\hline \multicolumn{10}{|l|}{ Household size } \\
\hline Avg size & 2.0 & 3.3 & 3.4 & 3.6 & 4.3 & 4.5 & 4.0 & 4.6 & 3.2 \\
\hline
\end{tabular}

Source: Spanish Survey of the 1998 European Community Household Panel

The summary statistics reported in Table 4 also show unambiguously that capital income is the most unequally distributed of the three variables, and that income is the least unequally distributed of the three. As we have already mentioned, this is partly because over $70 \%$ of the sample households report that they own the houses in which they live and the Europanel does not impute any rent to owner-occupied houses. 
Table 3 Spanish households ranked by capital income

\begin{tabular}{|c|c|c|c|c|c|c|c|c|}
\hline & \multirow{2}{*}{$\frac{\text { The poor }}{0-40}$} & \multicolumn{3}{|c|}{ Quintiles } & \multicolumn{3}{|c|}{ The rich } & \multirow[t]{2}{*}{ All } \\
\hline & & $\overline{40-60}$ & $60-80$ & $80-100$ & $\overline{10-5}$ & $5-1$ & $\overline{1}$ & \\
\hline \multicolumn{9}{|c|}{ Minimum and maximum income $\left(\times 10^{3}\right.$ euros $)$} \\
\hline Min capital inc & 0 & 0 & 0.01 & 0.09 & 0.62 & 2.37 & 19.56 & 0 \\
\hline Max capital inc & 0 & 0.01 & 0.09 & 87.15 & 2.36 & 18.03 & 87.15 & 87.15 \\
\hline \multicolumn{9}{|c|}{ Average income, earnings, capital income and transfers $\left(\times 10^{3}\right.$ euros $)$} \\
\hline Avg income & 13.60 & 13.90 & 15.18 & 24.42 & 23.35 & 25.35 & 66.11 & 16.14 \\
\hline Avg earnings & 9.62 & 10.22 & 10.67 & 15.33 & 16.41 & 14.76 & 21.05 & 11.09 \\
\hline Avg capital inc & 0 & 0.00 & 0.03 & 3.65 & 1.25 & 5.42 & 41.68 & 0.74 \\
\hline Avg transfers & 3.98 & 3.68 & 4.48 & 5.43 & 5.70 & 5.17 & 3.37 & 4.31 \\
\hline \multicolumn{9}{|c|}{ Shares of the sample totals (\%) } \\
\hline Income & 33.7 & 17.2 & 18.8 & 30.3 & 7.2 & 6.3 & 4.1 & 100 \\
\hline Earnings & 34.6 & 18.5 & 19.3 & 27.7 & 7.3 & 5.4 & 1.9 & 100 \\
\hline Cap inc & 0 & 0.0 & 0.8 & 99.2 & 8.5 & 29.7 & 57.2 & 100 \\
\hline Transfers & 37.1 & 16.9 & 20.8 & 25.2 & 6.6 & 4.9 & 0.8 & 100 \\
\hline \multicolumn{9}{|l|}{ Income sources (\%) } \\
\hline Labor & 70.6 & 73.8 & 70.2 & 62.8 & 70.2 & 58.2 & 31.9 & 68.7 \\
\hline Capital & 0 & 0.0 & 0.2 & 14.9 & 5.4 & 21.4 & 63.1 & 4.6 \\
\hline Transfers & 29.4 & 26.2 & 29.7 & 22.2 & 24.4 & 20.4 & 5.1 & 26.7 \\
\hline \multicolumn{9}{|l|}{ Age $(\%)$} \\
\hline$\leq 30$ & 11.9 & 15.4 & 9.3 & 6.8 & 7.2 & 3.5 & 3.1 & 11.1 \\
\hline $31-45$ & 35.2 & 35.5 & 40.9 & 29.0 & 28.0 & 24.0 & 1.5 & 35.1 \\
\hline $46-65$ & 29.9 & 29.7 & 31.5 & 42.5 & 44.9 & 46.6 & 78.5 & 32.7 \\
\hline$>65$ & 22.9 & 19.4 & 18.4 & 21.7 & 19.9 & 25.9 & 16.8 & 21.1 \\
\hline Avg age & 50.0 & 48.1 & 48.8 & 52.5 & 51.7 & 55.0 & 62.0 & 49.9 \\
\hline \multicolumn{9}{|l|}{ Education (\%) } \\
\hline No-primary & 18.6 & 14.0 & 13.0 & 8.6 & 3.8 & 7.5 & 17.3 & 14.6 \\
\hline Primary & 53.1 & 54.7 & 54.1 & 43.3 & 47.3 & 37.9 & 4.0 & 51.7 \\
\hline Secondary & 17.6 & 18.9 & 20.2 & 20.4 & 19.1 & 22.8 & 0 & 18.9 \\
\hline College & 10.6 & 12.3 & 12.7 & 27.8 & 29.7 & 31.8 & 78.7 & 14.8 \\
\hline \multicolumn{9}{|c|}{ Employment status (\%) } \\
\hline Worker & 48.2 & 48.3 & 48.6 & 44.4 & 49.9 & 37.0 & 9.4 & 47.5 \\
\hline Self-employed & 12.1 & 15.3 & 17.2 & 20.6 & 15.9 & 22.8 & 71.7 & 15.5 \\
\hline Retired & 19.1 & 17.0 & 15.8 & 21.5 & 21.0 & 23.8 & 16.5 & 18.5 \\
\hline Non-worker & 20.7 & 19.3 & 18.4 & 13.5 & 13.2 & 16.3 & 2.4 & 18.5 \\
\hline \multicolumn{9}{|l|}{ Marital status (\%) } \\
\hline Married & 65.3 & 66.9 & 68.4 & 68.0 & 68.7 & 69.4 & 93.2 & 66.8 \\
\hline Single male & 13.9 & 14.2 & 14.1 & 16.3 & 14.1 & 14.0 & 4.4 & 14.5 \\
\hline Single female & 20.8 & 18.8 & 17.5 & 15.7 & 17.3 & 16.6 & 2.4 & 18.7 \\
\hline \multicolumn{9}{|l|}{ Household size } \\
\hline Avg size & 3.1 & 3.1 & 3.3 & 3.4 & 3.1 & 3.0 & 7.3 & 3.2 \\
\hline
\end{tabular}

Source: Spanish Survey of the 1998 European Community Household Panel

\section{Skewness}

We report three measures of the skewness of the income, earnings, and capital income distributions in Table 5. These measures establish that all three distributions are significantly skewed to the right. They also show that capital income is significantly more skewed to the right than either earnings or income. 


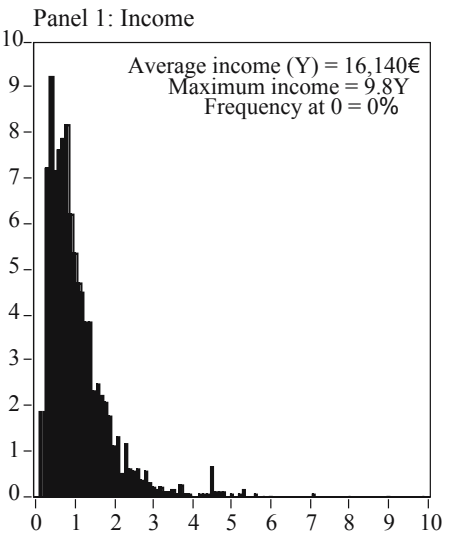

Panel 2: Earnings (all households)

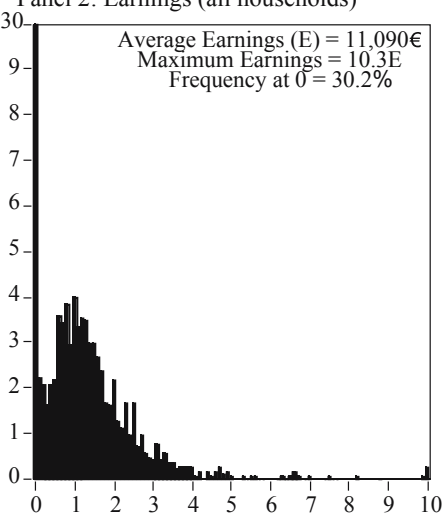

Panel 3: Capital Income
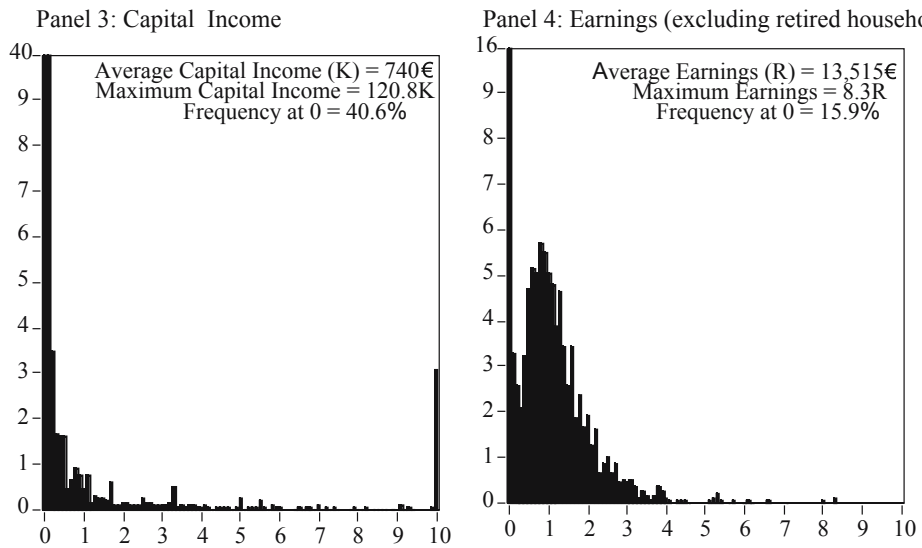

Fig. 1 The Spanish distributions of income, earnings and capital income. Panel 1 Income, Panel 2 Earnings (all households), Panel 3 Capital income, Panel 4 Earnings (excluding retired households). Levels displayed in the horizontal axes have been normalized dividing by the mean. The last observations represent the frequencies of households with more than 10 times the corresponding averages. Source: Spanish Survey of the 1998 European Community Household Panel

In the first two rows of Table 5, we report the percentiles in which the means are located and the mean-to-median ratios. In symmetric distributions, the mean is located in the 50th percentile and, consequently, the mean-to-median ratio is one. As the skewness to the right of a variable increases, the location of its mean moves to a higher percentile, and its mean-to-median ratio also increases. According to these two statistics, capital income is by far the most skewed to the right of the three variables, and the skewness of earnings and income are very similar. Specifically, while the locations of the means suggest that income 


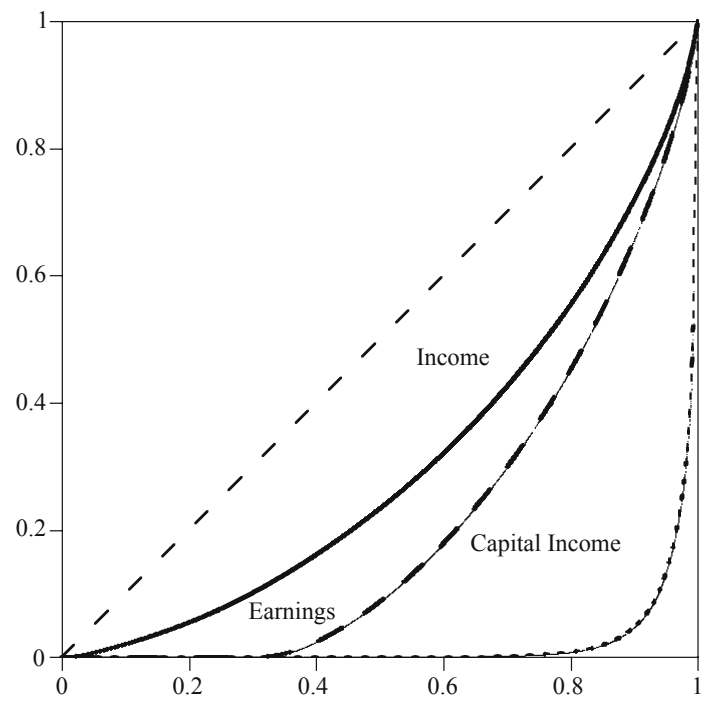

Fig. 2 The Lorenz curves of income, earnings, and capital income. Source: Spanish Survey of the 1998 European Community Household Panel

is somewhat more skewed to the right than earnings, the mean to median ratios indicate that the opposite is the case.

Finally, in the last row of Table 5, we report the skewness coefficient proposed by Fisher. This statistic is defined as $\gamma=\sum_{i} f_{i}\left(x_{i}-\bar{x}\right)^{3} / \sigma^{3}$, where $f_{i}$ is the relative frequency of realization $i$, and $\bar{x}$ and $\sigma$ are the mean and the standard deviation of the distribution. This coefficient is zero for symmetric unimodal distributions, it is positive for unimodal distributions that are skewed to the right, and it increases as right-hand skewness of the distributions increases. This statistic confirms that all three distributions are significantly skewed to the right, that capital income is, by far, the most skewed, and that income is somewhat more skewed than earnings.

\section{Correlation}

In Table 6 we report the correlation coefficients between income, earnings, capital income, and transfers. The data shows that all four variables are positively correlated, albeit to varying degrees. They also show that the correlation between earnings and capital income is low (0.10).

The large positive correlation between income and earnings ( 0.84$)$ is not surprising since earnings account for a the lion share of income (69\% on average). The significant negative correlation between earnings and transfers $(-0.36)$ can have various interpretations. First, it is further evidence of the large role played 
Table 4 The Concentration of the income, earnings, and capital income distributions

\begin{tabular}{lrrr}
\hline & Income & Earnings & Capital income \\
\hline Gini index & 0.39 & 0.57 & 0.95 \\
Coefficient of variation & 0.81 & 1.13 & 6.12 \\
Top 1\%/Bottom $60 \%$ & 9.32 & 21.36 & 96,848 \\
\hline
\end{tabular}

Source: Spanish Survey of the 1998 European Community Household Panel

Table 5 The skewness of the income, earnings and capital income distributions

\begin{tabular}{lrrr}
\hline & Income & Earnings & Capital income \\
\hline Location of Mean (\%) & 62 & 58 & 91 \\
Mean/Median & 1.28 & 1.30 & 2,105 \\
Skewness & 2.5 & 2.0 & 9.9 \\
\hline
\end{tabular}

Source: Spanish Survey of the 1998 European Community Household Panel

Table 6 The correlation between income and its components

\begin{tabular}{lrrrr}
\hline & Income & Earnings & Capital income & Transfers \\
\hline Income & 1.00 & 0.84 & 0.44 & 0.09 \\
Earnings & 0.84 & 1.00 & 0.10 & -0.36 \\
Capital income & 0.44 & 0.10 & 1.00 & 0.00 \\
Transfers & 0.09 & -0.36 & 0.00 & 1.00 \\
\hline
\end{tabular}

Source: Spanish Survey of the 1998 European Community Household Panel

by retirement pensions. If we exclude retirement pensions from our measure of transfers, this correlation drops to -0.12 . The remaining negative correlation could be evidence that transfers are indeed going to the most needy, or that the many of the transfer recipients choose not to work.

\section{The poor and the rich}

As we have already mentioned, the common usage of the concepts of the poor and the rich is somewhat ambiguous. To clarify this ambiguity, we distinguish between the poor and the rich in terms of income, earnings, and capital income, and we discuss some of the facts reported in Tables 1,2 and 3. We organize these facts into two groups: those that pertain to the households in the bottom tails of the distributions, which we refer to generically as the poor, and those that pertain to the households that in the top tails of the distributions, which we refer to generically as the rich. We have chosen this organization criterion because we think that one of the hardest tasks faced by any theory of inequality is to account for both tails of the distributions simultaneously. 
Table 7 The income poor

\begin{tabular}{|c|c|c|c|c|}
\hline \multicolumn{5}{|c|}{ Average income, earnings, capital income and transfers (euros) } \\
\hline & $Y$ & $E$ & $K$ & $\underline{Z}$ \\
\hline Bottom 1 & 189 & 125 & 18 & 45 \\
\hline Bottom 5 & 2,136 & 695 & 119 & 1,322 \\
\hline Bottom 20 & 4,403 & 1,064 & 88 & 3,251 \\
\hline All & 16,140 & 11,094 & 736 & 4,311 \\
\hline \multicolumn{5}{|c|}{ Shares of the sample totals (\%) } \\
\hline & $Y$ & $E$ & $K$ & $\underline{Z}$ \\
\hline Bottom 1 & 0.0 & 0.0 & 0.0 & 0.0 \\
\hline Bottom 5 & 0.7 & 0.3 & 0.8 & 1.5 \\
\hline Bottom 20 & 5.4 & 1.9 & 2.4 & 14.9 \\
\hline \multicolumn{5}{|c|}{ Income sources $(\%)$} \\
\hline & & Labor & Capital & Transfers \\
\hline Bottom 1 & & 66.4 & 9.7 & 24.0 \\
\hline Bottom 5 & & 32.5 & 5.6 & 61.9 \\
\hline Bottom 20 & & 24.2 & 2.0 & 73.8 \\
\hline All & & 68.7 & 4.6 & 26.7 \\
\hline \multicolumn{5}{|l|}{ Age (\%) } \\
\hline & $<30$ & $31-45$ & $46-65$ & $>65$ \\
\hline Bottom 1 & 6.0 & 40.4 & 42.7 & 10.8 \\
\hline Bottom 5 & 18.0 & 30.9 & 33.8 & 17.4 \\
\hline Bottom 20 & 12.9 & 18.3 & 23.3 & 45.4 \\
\hline All & 11.1 & 35.1 & 32.7 & 21.1 \\
\hline \multicolumn{5}{|c|}{ Education (\%) } \\
\hline & None & Primary & Highschool & College \\
\hline Bottom 1 & 6.9 & 53.4 & 28.9 & 10.7 \\
\hline Bottom 5 & 20.0 & 61.7 & 13.0 & 5.4 \\
\hline Bottom 20 & 30.8 & 56.3 & 6.9 & 5.9 \\
\hline All & 14.6 & 51.7 & 18.9 & 14.8 \\
\hline \multicolumn{5}{|c|}{ Employment status (\%) } \\
\hline & Worker & Self-employed & Retired & Non-worker \\
\hline Bottom 1 & 7.5 & 69.8 & 0 & 22.7 \\
\hline Bottom 5 & 14.6 & 31.9 & 6.6 & 46.9 \\
\hline Bottom 20 & 14.6 & 15.9 & 29.5 & 40.1 \\
\hline All & 47.5 & 15.5 & 18.5 & 18.5 \\
\hline \multicolumn{5}{|c|}{ Marital status (\%) } \\
\hline & & Married & Single male & Single female \\
\hline Bottom 1 & & 65.7 & 3.0 & 31.4 \\
\hline Bottom 5 & & 58.7 & 12.1 & 29.2 \\
\hline Bottom 20 & & 43.3 & 14.7 & 42.0 \\
\hline All & & 66.8 & 14.5 & 18.7 \\
\hline
\end{tabular}

Source: Spanish Survey of the 1998 European Community Household Panel

The income-poor

We start with the income-poor. In the first and fourth columns of Table 1 we report some of the economic characteristics of the bottom percentile and the bottom quintile of the income distribution. In Table 7 we reorganize these facts 
for the sake of clarity, and we extend them with those that pertain to the bottom $5 \%$ of the income distribution, and to the total sample.

We find that every household in the 1998 Spanish survey of the Europanel reports a strictly positive income. This fact contrasts sharply with the $30.2 \%$ of the sample households who report zero earnings, and the $40.6 \%$ of the households who report zero capital income. If we exclude from the sample the households headed by retirees, we find that $15.9 \%$ of the total sample report a positive income and zero earnings. Naturally, the income of these households is either capital income or transfers. These facts suggest that in Spain a significant number of working-age households has some form of a safety net, either public or private, that allows them to live without working.

We find that the households in the bottom percentile of the income distribution (the income-poorest) are extremely poor, that they are mostly selfemployed, middle-aged, reasonably well educated, and that many of those households are headed by single females. Moreover, we find that the Spanish income-poorest receive a surprisingly small share of their income from transfers. We discuss each of this features in the paragraphs immediately below.

Specifically, the average income of the income-poorest was only 189 euros which is $1.2 \%$ of the sample average household income, and which corresponds to approximately $60 \%$ of the $\$ 1$ per day poverty line (304 euros). ${ }^{7}$ This number increases by more than 11 times when we move to the bottom $5 \%$ of the distribution (2,136 euros), and it more than doubles again when we move to the bottom quintile (4,403 euros, see Fig. 3).

Amongst the income-poorest, a striking $69.8 \%$ of the household-heads report self-employment to be their primary occupation. This number is more than four times larger than the sample average $(15.5 \%)$, and it decreases rapidly as we move to the bottom $5 \%$ and the bottom quintile of the income distribution (31.9 and $15.9 \%$, respectively).

The average age of the income poorest (48.0) is only slightly smaller than the sample average (49.9) and, perhaps surprisingly, amongst the 1998 incomepoorest there were no households headed by retirees. In the bottom $5 \%$ of the income distribution the share of retirees was still only $6.6 \%$, while in the bottom quintile this number had jumped to $29.5 \%$. These facts suggest that the Spanish pension system makes it possible for the elderly to escape from extreme income poverty.

Another surprising fact is that only $6.9 \%$ of the heads of the income-poorest households have not completed their primary education. This number is significantly smaller than the corresponding ones for both the bottom $5 \%$ and the bottom quintile of the distribution ( $20.0 \%$ and $30.8 \%$, respectively). In contrast, large shares of the income-poorest had completed both highschool (28.9\%) and college $(10.7 \%)$. In the bottom quintile of the distribution, these numbers were $6.9 \%$ and $5.9 \%$, respectively.

\footnotetext{
7 This number was obtained using a 1 euro $=\$ 1.20$ exchange rate.
} 


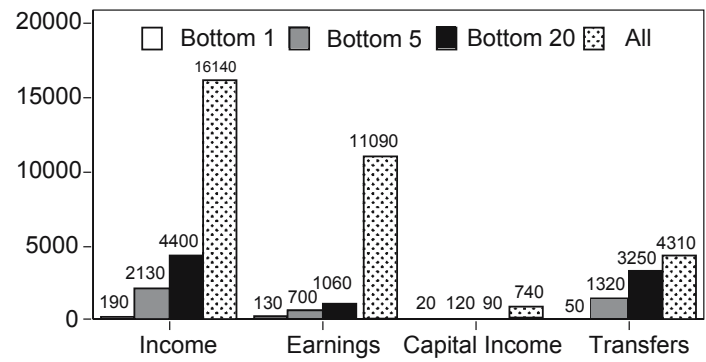

Fig. 3 Income, earnings, capital income, and transfers of the income poor (1997 euros). Source: Spanish Survey of the 1998 European Community Household Panel

Many income poor households were headed by single females: around 30\% of those in the bottom percentile and in the bottom 5\%, and a startling $42 \%$ of those in the bottom quintile. These numbers are significantly larger than the $18.7 \%$ figure that we obtain for the total sample.

Finally, the 1998 Spanish Europanel data show that the income-poorest obtained only $24 \%$ of their income from transfers, and that this number jumps to $62 \%$ and $74 \%$ when we move to the bottom $5 \%$ and to the bottom quintile of the income distribution. This could mean that some of the income-poorest households are excluded from social assistance and other non-contributive public transfers.

\section{The earnings-poor}

We find that $30.2 \%$ of the Spanish Europanel households report zero labor earnings. In spite of this fact, the average income of these households is fairly large (8,730 euros), and it would put them in the second quintile of the income distribution. This group of households receive the lion's share of total transfers $(57.1 \%)$. Moreover, transfers account for almost all of this group's income (93.9\%).

As could be expected, the heads of the earnings-poor households tend to be old $(67.7 \%$ of them are over 65$)$, uneducated $(33.5 \%$ of them have not completed their primary education), and are either retired or non-workers (58.6 and $35.6 \%$ ). Many of the households in this group are headed by single women (34.4\%), and the average household size of this group ( 2.0 people) is rather small. This is partly because this group of households includes a significant number of widows who live alone. Specifically, $8.7 \%$ of the sample households were headed by widows and $74.7 \%$ of these widows report that they live alone.

The capital income-poor

We find that $40.6 \%$ of the Spanish Europanel households report zero capital income. As we have already mentioned, this is partly because over $70 \%$ of the 
sample households report that they own the houses in which they live and the Europanel does not impute any rent to owner-occupied houses. We also find that in every dimension of inequality this group of households is very close to the sample averages. This is because capital income is extremely concentrated, and because the share of income accounted for by capital income is very small ( $4.6 \%$ on average).

The income-rich

We now turn to the income-rich. In the nineth and twelfeth columns of Table 1 we report some of the economic characteristics of the top quintile and the top percentile of the income distribution, respectively. In Table 8 we reorganize these facts for the sake of clarity, and we extend them with those that pertain to the the top $5 \%$, and to the total sample.

We find that the households in the top percentile of the income distribution (the income-richest) are income, earnings, and, especially, capital income rich. They earn almost half of the total sample capital income. Their household heads they are mostly self-employed and between 46 and 65 years old, and almost everyone of them has gone to college and is married.

More specifically, we find that the households in the top income percentile earn on average about 80,000 euros per year which is five times the sample's average income, and that this number drops to 3.5 and 2.2 times the sample's average (56,000 and 36,000 euros) when we consider the households in the top $5 \%$ and in the top quintile of the income distribution, respectively (see Fig. 4).

We also find that capital income is extremely concentrated in the hands of the income-rich. Specifically, the households in the top percentile of the income distribution receive $48.1 \%$ of the total sample capital income, and this number increases to $60.7 \%$ and $76.2 \%$, when we consider the top 5\% and the top quintile. These facts notwithstanding, the income-richest receive a share of total transfers $(1.0 \%)$ that is significantly larger than the share received by the bottom percentile $(0.01 \%)$.

As many as $86.1 \%$ of the income-rich household heads belong to the 46-65 age cohort, while only $1.3 \%$ are under 30 and $3.4 \%$ are over 65 . The shares of the very young and the very old increase sharply as we move towards the top quintile of the distribution.

A very large number of household heads in the top percentile of the income distribution $(85.0 \%)$ report that they have completed college. This number drops to 61.1 and $41.5 \%$ when we consider the households in the top five percent and in the top quintile of the distribution, respectively.

As was the case with the income-poorest, a large majority $(60.6 \%)$ of the household heads in the top percentile of the income distribution report that self-employment is their primary occupation, no-one is a non-worker, and only $1.6 \%$ are retired. These numbers contrast sharply with the sample averages that are $15.5,18.5$, and $18.5 \%$. 
Table 8 The income rich

\begin{tabular}{|c|c|c|c|c|}
\hline \multicolumn{5}{|c|}{ Average income, earnings, capital income and transfers (euros) } \\
\hline & $Y$ & $E$ & $K$ & $\underline{Z}$ \\
\hline Top 1 & 80,349 & 49,527 & 27,555 & 3,267 \\
\hline Top 5 & 56,344 & 41,639 & 8,922 & 5,784 \\
\hline Top 20 & 35,969 & 28,140 & 2,802 & 5,027 \\
\hline All & 16,140 & 11,094 & 736 & 4,311 \\
\hline \multicolumn{5}{|c|}{ Shares of the sample totals (\%) } \\
\hline & $Y$ & $E$ & $K$ & $Z$ \\
\hline Top 1 & 6.4 & 5.7 & 48.1 & 1.0 \\
\hline Top 5 & 17.5 & 18.8 & 60.7 & 6.7 \\
\hline Top 20 & 44.6 & 50.8 & 76.2 & 23.8 \\
\hline \multicolumn{5}{|c|}{ Income sources (\%) } \\
\hline & & Labor & Capital & Transfers \\
\hline Top 1 & & 61.6 & 34.3 & 4.2 \\
\hline Top 5 & & 73.9 & 15.8 & 10.3 \\
\hline Top 20 & & 78.2 & 7.8 & 14.0 \\
\hline All & & 68.7 & 4.6 & 26.7 \\
\hline \multicolumn{5}{|l|}{ Age (\%) } \\
\hline & $<30$ & $31-45$ & $46-65$ & $>65$ \\
\hline Top 1 & 1.3 & 9.3 & 86.1 & 3.4 \\
\hline Top 5 & 2.7 & 32.5 & 59.4 & 5.4 \\
\hline Top 20 & 7.0 & 42.6 & 45.3 & 5.1 \\
\hline All & 11.1 & 35.1 & 32.7 & 21.1 \\
\hline \multicolumn{5}{|c|}{ Education (\%) } \\
\hline & None & Primary & Highschool & College \\
\hline Top 1 & 9.5 & 5.5 & 0 & 85.0 \\
\hline Top 5 & 0.8 & 18.6 & 19.6 & 61.1 \\
\hline Top 20 & 2.2 & 33.0 & 23.3 & 41.5 \\
\hline All & 14.6 & 51.7 & 18.9 & 14.8 \\
\hline \multicolumn{5}{|c|}{ Employment status (\%) } \\
\hline & Worker & Self-employed & Retired & Non-worker \\
\hline Top 1 & 37.8 & 60.6 & 1.6 & 0 \\
\hline Top 5 & 61.2 & 33.4 & 4.1 & 1.4 \\
\hline Top 20 & 68.8 & 17.7 & 4.8 & 8.7 \\
\hline All & 47.5 & 15.5 & 18.5 & 18.5 \\
\hline \multicolumn{5}{|c|}{ Marital status (\%) } \\
\hline & & Married & Single male & Single female \\
\hline Top 1 & & 91.7 & 3.4 & 4.9 \\
\hline Top 5 & & 82.4 & 13.9 & 3.7 \\
\hline Top 20 & & 76.5 & 14.2 & 9.3 \\
\hline All & & 66.8 & 14.5 & 18.7 \\
\hline
\end{tabular}

Source: Spanish Survey of the 1998 European Community Household Panel

Finally, the income-rich are mostly married, and they tend to live in large households. Specifically, $91.7 \%$ of the household heads in the top $1 \%$ of the income distribution are married, and the average size of these households is a striking 7.3 people, while the sample averages are $66.8 \%$ and 3.2 people. If we consider the top income quintile, these three numbers drop somewhat: $76.5 \%$ are married, and their average household size drops to 4.4 people. 


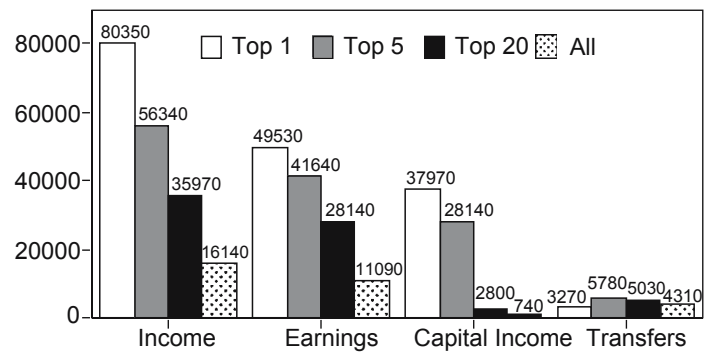

Fig. 4 Income, earnings, capital income, and transfers of the income rich (1997 euros). Source: Spanish Survey of the 1998 European Community Household Panel

The earnings-rich

Next we consider the earnings-rich. The average earnings of the households in the the top quintile (the earnings-rich) are 2.7 times the sample's average, and and the average earnings of those in the top percentile of the earnings distribution (the earnings-richest) are 6.4 times the sample's average earnings. We report some of their economic characteristics in the last columns of Table 2.

We find that the shares of income accounted for by capital income and transfers are rather small for these two groups of households. Specifically, capital income accounts for $6.4 \%$ of the income of the earnings-rich, and transfers account for $4.5 \%$. In the case of the earnings-richest these numbers are 2.2 and $2.7 \%$, respectively.

We also find that most of the earnings-richest (91.3\%) are married, perhaps to a spouse who gives them extra incentives to work, and that they tend to live in large households. Specifically, the average household size in the top quintile of the earnings distribution is 4.3 people, while that in the bottom $30 \%$ of the earnings distribution is only 2.0 people. In fact, both the average share of married households and the average household size of the quintiles of the earnings partition are clearly increasing in earnings (see Table 2).

The capital income-rich

Finally, we consider the capital income-rich. We report some of their economic characteristics in the last columns of Table 3. That table shows that in the 1998 Spanish Survey of the Europanel capital income is extremely concentrated in the hands of very few households. Specifically, the households who belong to the top percentile of the capital income distribution (the capital income-richest) earn $57.2 \%$ of the total sample capital income, and those who belong to the top quintile (the capital income-rich) earn an impressive $99.2 \%$ of the total. When compared with the rest of the households in the sample, the average capital income of these households is also very large. Specifically, the capital incomerich earn five times the sample average, and the capital income-richest earn as much as 57 times the sample average. 
These two facts notwithstanding, capital income accounts for a relatively small share of total income, even for the households in the top tail of the capital income distribution. This share is $14.9 \%$ for the households in the top quintile of the capital income distribution, and $63.1 \%$ for the households in the top percentile.

Another outstanding feature of the capital income partition is that it is mostly the old who are capital income rich. Specifically, the share of households in the top capital income quintile who are older than 45 is $64.2 \%$, and the share of the households in the top capital income percentile who belong to that age group is $95.4 \%$.

Finally, very large proportions of the capital income-richest are married (93.2\%), have obtained a college degree (78.7\%), and are self-employed (71.7\%).

\section{Age and inequality}

Some of the income differences across households can be attributed to age. ${ }^{8}$ Two main methods can be used to quantify the relationship between age and inequality. One method is to compare the lifetime inequality statistics with their yearly counterparts. To implement this method, we must follow a sample of households through their entire lifecycles. Unfortunately, the Europanel is not long enough for this purpose, and this forces us to use cross-sectional data to quantify the age-related differences in inequality.

Specifically, we do the following: we partition the 1998 Spanish Europanel sample into 11 cohorts according to the age of the household heads, we compute the relevant statistics for each cohort, and we compare them with the corresponding statistics for the entire sample. These statistics are the cohort average income, earnings, capital income, and transfers and their respective Gini indexes; the average shares of income earned by each cohort from various income sources; the number of people per household in each cohort and the relative cohort size. We report these statistics in Table 9.

In Panel 1 of Fig. 5, we represent the average income, earnings, capital income, and transfers of each cohort. As this figure illustrates, earnings displays the typical hump-shape conventionally attributed to the life-cycle. Perhaps more interestingly, the life-cycle patterns of capital income and transfers are rather different. More specifically, average cohort capital income is moderately increasing until age 60, it jumps in the 61-65 age cohort when households cash in their retirement plans, and it drops again thereafter. On the other hand, average cohort transfers display a mild U-shape. They are somewhat high in the under- 25 age cohorts, they decrease until the $41-45$ cohort, and they increase thereafter until they reach the maximum in the 66-70 age group. Altogether,

\footnotetext{
8 In fact, a large part of the quantitative heterogeneous-agent literature uses models in which differences in people's age are the main source of economic inequality. See, for example, Auerbach and Kotlikoff (1987), Fullerton and Rogers (1993), and Ríos-Rull (1996).
} 
Table 9 Spanish households partitioned by age

\begin{tabular}{|c|c|c|c|c|c|c|c|c|c|c|c|c|}
\hline \multirow[t]{2}{*}{ Age } & \multicolumn{4}{|c|}{ Averages (1997 euros) } & \multicolumn{3}{|c|}{ Gini indexes } & \multicolumn{3}{|c|}{ Sources (\%) } & \multirow[t]{2}{*}{$\mathrm{Size}^{\mathrm{e}}$} & \multirow[t]{2}{*}{$H(\%)^{f}$} \\
\hline & $Y^{\mathrm{a}}$ & $E^{\mathrm{b}}$ & $K^{\mathrm{c}}$ & $Z^{\mathrm{d}}$ & $\bar{Y}$ & $E$ & $K$ & $\bar{E}$ & $K$ & $Z$ & & \\
\hline$\leq 25$ & 9,517 & 4,968 & 259 & 4 & & 0 & 0 & & 2.7 & & & 2.8 \\
\hline$\overline{26}-30$ & 14,938 & 11,039 & 148 & 3,751 & 0.32 & 0.40 & 0.94 & 73.9 & 1.0 & 25.1 & 3.0 & 8.3 \\
\hline $31-35$ & 16,991 & 13,107 & 176 & 3,709 & 0.31 & 0.36 & 0.92 & 77.1 & 1.0 & 21.8 & 3.5 & 12.4 \\
\hline $36-40$ & 16,908 & 14,202 & 234 & 2,472 & & & & & 1.4 & & & 11.9 \\
\hline $41-45$ & 18,795 & 16,327 & 272 & 2,196 & 0.34 & 0.40 & 0.94 & 87.0 & 1.4 & 11.7 & 3.9 & 10.8 \\
\hline $46-50$ & 19,841 & 17,055 & 480 & & 0.37 & 0.43 & 0.92 & 8 & 2.4 & 11 & 4.0 & 10.3 \\
\hline $51-55$ & 20,985 & 17,569 & 614 & 2,803 & 0.34 & 0.41 & 0.91 & 83.7 & 2.9 & 13.4 & 4.0 & 9.1 \\
\hline $56-60$ & 17,523 & 12,553 & 1,060 & 3,909 & 0.40 & 0.54 & 0.94 & 71.6 & 6.1 & 22.3 & 3.8 & 6.2 \\
\hline $61-65$ & 19,900 & 10,234 & 4,548 & 5,118 & 0.46 & 0.66 & 0.82 & 51.4 & 22.9 & 25.7 & 3.2 & 7.1 \\
\hline $66-70$ & 10,759 & 1,003 & 752 & 9,004 & 0.35 & 0.97 & 0.93 & 9.3 & 7.0 & 83.7 & 1.9 & 5.8 \\
\hline$>70$ & 9,184 & 229 & 665 & 8,290 & 0.34 & 0.99 & 0.95 & 2.5 & 7.2 & 90.3 & 1.7 & 15.3 \\
\hline Total & 16,140 & 11,094 & 736 & 4,311 & 0.39 & 0.57 & 0.95 & 68.7 & 4.6 & 26.7 & 3.2 & 100 \\
\hline
\end{tabular}

Source: Spanish Survey of the 1998 European Community Household Panel

ancome

${ }^{\mathrm{b}}$ Earnings

${ }^{\mathrm{c}}$ Capital income

dransfers

e Average number of persons per household

${ }^{\mathrm{f}}$ Percentage number of households per age group

the life-cycle behavior of these variables implies that income also displays the familiar life-cycle hump-shape, with an extra peak in the 61-65 cohort.

In Panel 2 of Fig. 5, we represent the Gini indexes of income, earnings, and capital income of the age cohorts. We find that the Gini indexes of income and capital income of the age cohorts are very similar to those of the total sample. On the other hand, the Gini index of earnings displays a strong U-shape. It is 0.57 for the under- 25 cohort, it stays around 0.40 until age 55 and it increases sharply thereafter to reach 0.99 in the over-70 age group. This finding is not surprising since the number of households whose earnings are zero jumps by a large amount around the retirement age.

In Panel 3 of Fig. 5, we represent the income sources of the age cohorts. Their shapes are also very characteristic. The share of income accounted for by earnings is clearly hump-shaped, it peaks at the 41-45 age group, and it drops sharply thereafter. The transfers share of income is clearly U-shaped. It drops from $45.1 \%$ in the under- 25 age cohort to $11.6 \%$ in the $46-50$ group and it increases sharply thereafter to reach $90.3 \%$ in the over- 70 cohort. Finally, the share of income accounted for by capital income is less than $3 \%$ until age 55 , it jumps to $22.9 \%$ in the $61-65$ age group, and it drops to about seven percent thereafter.

\section{Employment status and inequality}

To document the relationship between employment status and inequality, we partition the Spanish Europanel sample into workers, the self-employed, 
Panel 1: Averages (1997€)

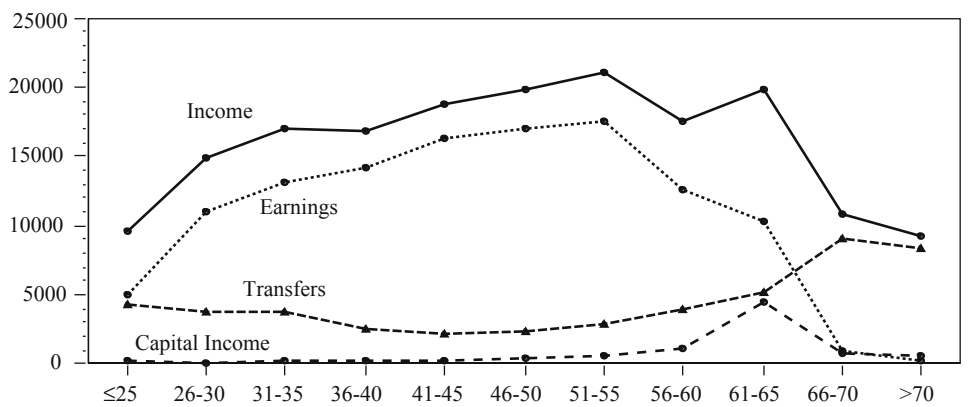

Panel 2: Gini Indexes

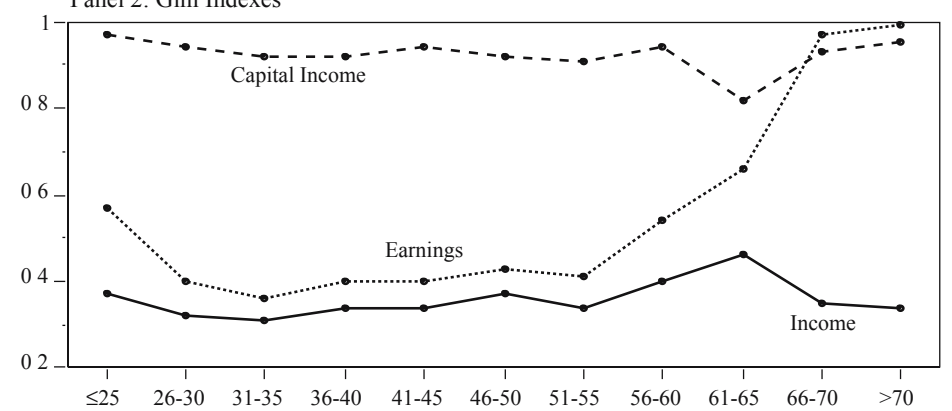

Panel 3: Sources of income (\%)

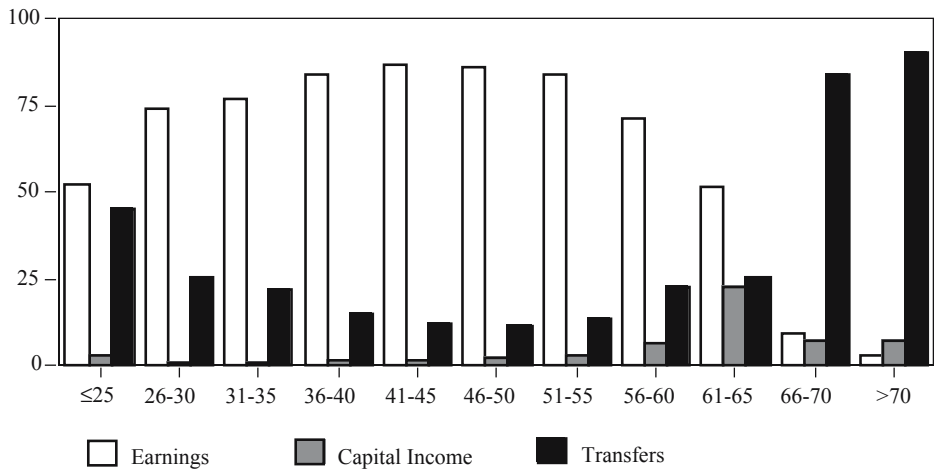

Fig. 5 Spanish households partitioned by age. Panel 1 Averages (1997 €), Panel 2 Gini indexes, Panel 3 Sources of income (\%). Source: Spanish Survey of the 1998 European Community Household Panel 
Table 10 Spanish households partitioned by employment status

\begin{tabular}{|c|c|c|c|c|c|c|c|c|c|c|c|c|}
\hline & \multicolumn{4}{|c|}{ Averages (1997 euros) } & \multicolumn{3}{|c|}{ Gini indexes } & \multicolumn{3}{|c|}{ Sources (\%) } & \multirow[t]{2}{*}{$S^{\mathrm{e}}$} & \multirow[t]{2}{*}{$\mathrm{H}^{\mathrm{f}}$} \\
\hline & $Y^{\mathrm{a}}$ & $E^{\mathrm{b}}$ & $K^{\mathrm{c}}$ & $Z^{\mathrm{d}}$ & $\bar{Y}$ & $E$ & $K$ & $E$ & $K$ & $Z$ & & \\
\hline Worker & 19,793 & 17,108 & 317 & 2,367 & 0.32 & 0.36 & 0.94 & 86.4 & 1.6 & 12.0 & 3.5 & 47.5 \\
\hline Self-employed & 18,728 & 13,472 & 2,456 & 2,800 & 0.45 & 0.44 & 0.90 & 71.9 & 13.1 & 15.0 & 4.2 & 15.5 \\
\hline Retired & 10,473 & 417 & 755 & 9,301 & 0.31 & 0.97 & 0.94 & 4.0 & 7.2 & 88.8 & 1.9 & 18.5 \\
\hline Non-worker & 10,259 & 4,327 & 354 & 5,578 & 0.40 & 0.79 & 0.95 & 42.2 & 3.4 & 54.4 & 2.9 & 18.5 \\
\hline Total & 16,140 & 11,094 & 736 & 4,311 & 0.39 & 0.57 & 0.95 & 68.7 & 4.6 & 26.7 & 3.2 & 100 \\
\hline
\end{tabular}

Source: Spanish Survey of the 1998 European Community Household Panel

${ }^{\mathrm{a}}$ Income

${ }^{\mathrm{b}}$ Earnings

${ }^{\mathrm{c}}$ Capital income

${ }^{\mathrm{d}}$ Transfers

${ }^{\mathrm{e}}$ Average number of persons per household

${ }^{\mathrm{f}}$ Percentage number of households per age group

retirees, and non-workers according to the occupation declared by the heads of the households. In Table 10 we report the average income, earnings, capital income, and transfers; the Gini indexes of the first three variables; the shares of income obtained from various sources; the number of people per household; and the relative group sizes for these four employment status groups, and for the entire sample.

In Panel 1 of Fig. 6, we represent the average income, earnings, capital income, and transfers of the employment status groups. It turns out that the differences across these groups are substantial. Workers make up $47.5 \%$ of the sample and they are by far the largest group. Their income is $23 \%$ higher than the sample average, and their earnings are $54 \%$ higher, but their average capital income and transfers are significantly smaller than the sample average. The self-employed households make up $15.5 \%$ of the sample, their average income is only $13 \%$ smaller than that of workers, but their average capital income is 7.7 times larger. The retirees account for $18.5 \%$ of the sample. Their average income is only $64.9 \%$ of the sample average, and it is made up mostly of capital income and transfers. Finally, households headed by a non-worker earn only slightly less income than the retirees, but their earnings are larger and their transfers smaller.

As Panel 2 of Fig. 6 illustrates, the Gini indexes of income, earnings, and capital income differ significantly across the employment status groups. Income is most equally distributed amongst workers and retirees, and most unequally distributed amongst the self-employed and the non-workers. Not surprisingly, earnings are most unequally distributed amongst the retirees and the non-workers. In contrast, the Gini indexes of capital income are very similar for all the employment status groups.

In Panel 3 of Fig. 6 we represent the income sources of the employment status groups. We find that the shares of income accounted for by labor, capital, and transfers also differ significantly with the primary occupation of the household heads. The most noteworthy features of this figure are the significant share of 
Panel 1: Averages (1997€)
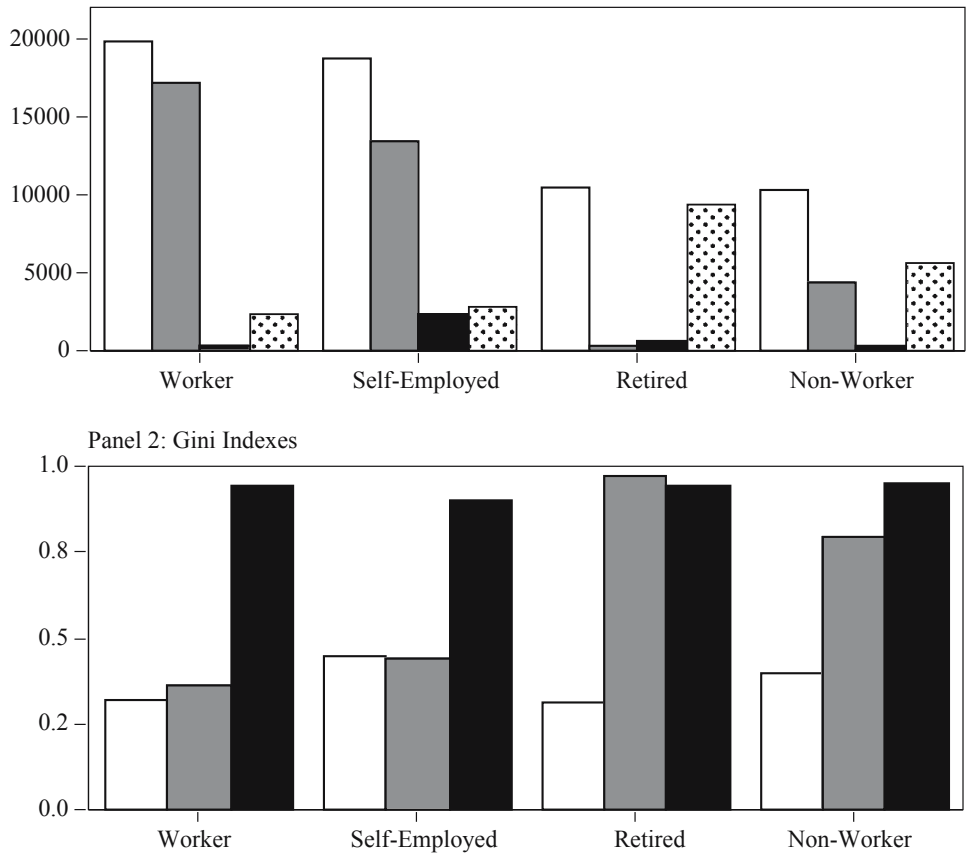

Panel 3: Sources of Income (\%)

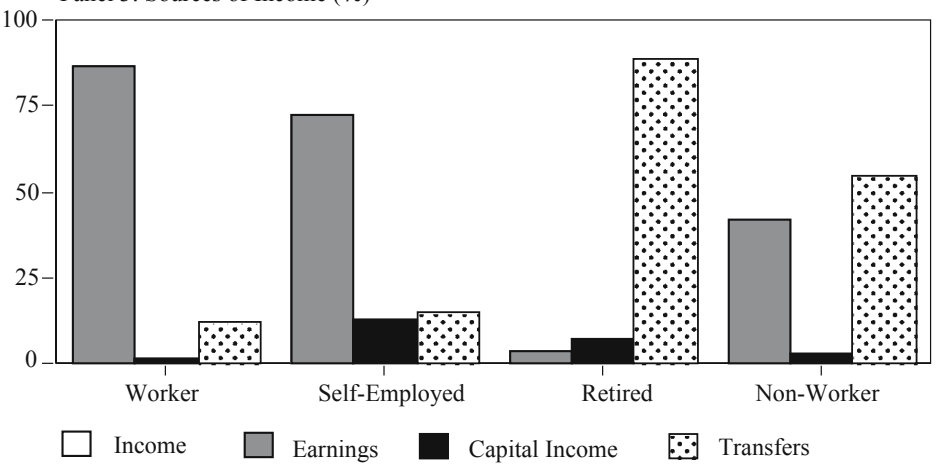

Fig. 6 Spanish household partitioned by employment status, Panel 1 Averages (1997 €), Panel 2 Gini indexes, Panel 3 Sources of income (\%). Source: Spanish Survey of the 1998 European Community Household Panel

capital income obtained by the self-employed (13.1\%), and the fact that labor income, presumably earned by the spouse, accounts for $42.2 \%$ of the income of the households headed by a non-worker. It is also interesting that this group is 
Table 11 Spanish households partitioned by education

\begin{tabular}{|c|c|c|c|c|c|c|c|c|c|c|c|c|}
\hline & \multicolumn{4}{|c|}{ Averages (1997 euros) } & \multicolumn{3}{|c|}{ Gini indexes } & \multicolumn{3}{|c|}{ Sources (\%) } & \multirow[t]{2}{*}{$S^{\mathrm{e}}$} & \multirow[t]{2}{*}{$\mathrm{H}^{\mathrm{f}}$} \\
\hline & $Y^{\mathrm{a}}$ & $E^{\mathrm{b}}$ & $K^{\mathrm{c}}$ & $Z^{\mathrm{d}}$ & $Y$ & $E$ & $K$ & $\bar{E}$ & $K$ & $Z$ & & \\
\hline No-Prim & 8,974 & 3,186 & 152 & 5,636 & 0.31 & 0.80 & 0.95 & 35.5 & 1.7 & 62.8 & 2.7 & 14.9 \\
\hline Primary & 13,610 & 9,070 & 317 & 4,223 & 0.35 & 0.56 & 0.94 & 66.6 & 2.3 & 31.0 & 3.3 & 51.5 \\
\hline Secondary & 18,163 & 13,899 & 428 & 3,836 & 0.31 & 0.42 & 0.92 & 76.5 & 2.4 & 21.1 & 3.2 & 18.9 \\
\hline College & 29,278 & 22,151 & 3,174 & 3,953 & 0.34 & 0.41 & 0.89 & 75.7 & 10.8 & 13.5 & 3.6 & 14.7 \\
\hline FP & 16,280 & 12,514 & 442 & 3,324 & 0.29 & 0.40 & 0.94 & 76.9 & 2.7 & 20.4 & 3.1 & 9.3 \\
\hline BUP & 20,009 & 15,257 & 415 & 4,337 & 0.32 & 0.43 & 0.90 & 76.2 & 2.1 & 21.7 & 3.3 & 9.5 \\
\hline Diplomatura & 22,279 & 17,174 & 1,261 & 3,843 & 0.30 & 0.38 & 0.92 & 77.1 & 5.7 & 17.3 & 3.2 & 5.8 \\
\hline Licenciatura & 33,824 & 25,383 & 4,416 & 4,024 & 0.33 & 0.40 & 0.84 & 75.1 & 13.1 & 11.9 & 3.8 & 8.9 \\
\hline Total & 16,140 & 11,094 & 736 & 4,311 & 0.39 & 0.57 & 0.95 & 68.7 & 4.6 & 26.7 & 3.2 & 100 \\
\hline
\end{tabular}

Source: Spanish Survey of the 1998 European Community Household Panel

${ }^{\text {a } I n c o m e}$

${ }^{\mathrm{b}}$ Earnings

${ }^{\mathrm{c}}$ Capital income

${ }^{\mathrm{d}}$ Transfers

e Average number of persons per household

${ }^{\mathrm{f}}$ Percentage number of households per age group

also the second largest recipient of transfers (54.4\%). Finally, we find that both the self-employed and the workers tend to belong to households that are larger than average.

\section{Education and inequality}

To document the relationship between education and inequality, we partition the 1998 Spanish Europanel sample into four main education groups based on the level of education attained by the head of the household. The first group, labeled No-Primary, includes the households whose head has not completed the mandatory primary education; the second group, labeled Primary, includes the households whose head has completed the primary education, but has not completed the secondary education; the third group, labeled Secondary, includes the households whose head has completed the secondary education, but has not obtained a college degree; and the fourth group, labeled College, includes the households whose head has obtained at least a college degree. We further partition the secondary education households into two groups: a group labeled $F P$ that includes the households whose head has completed technical highschool, and a group labeled $B U P$ that includes the households whose head has completed regular highschool. Finally we partition the college households into two groups: a group labeled Diplomatura that includes the households whose head has obtained a 3-year college degree, and a group labeled Licenciatura that includes the households whose head has obtained a 4 or 5 year college degree.

In Table 11, we report the averages for income, earnings, capital income, and transfers; the Gini indexes of the first three variables; the shares of income obtained from various sources; the number of people per household; and relative group sizes the for these education groups, and for the entire sample. 
Panel 1: Averages (1997€)

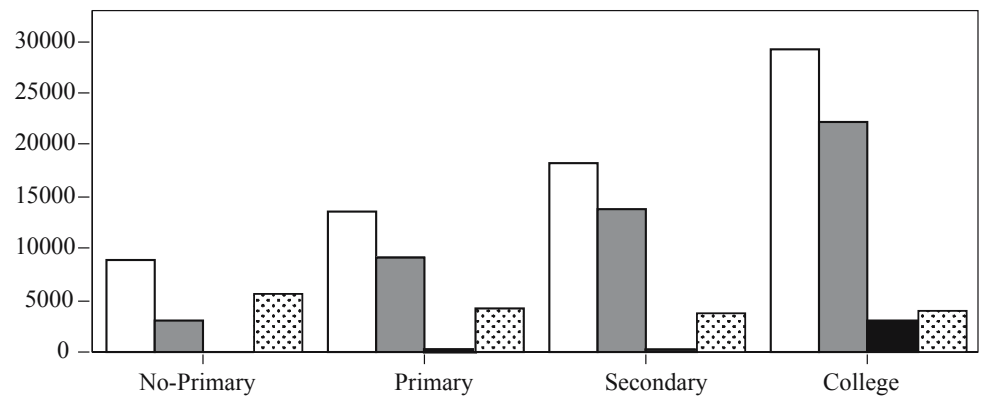

Panel 2: Gini Indexes

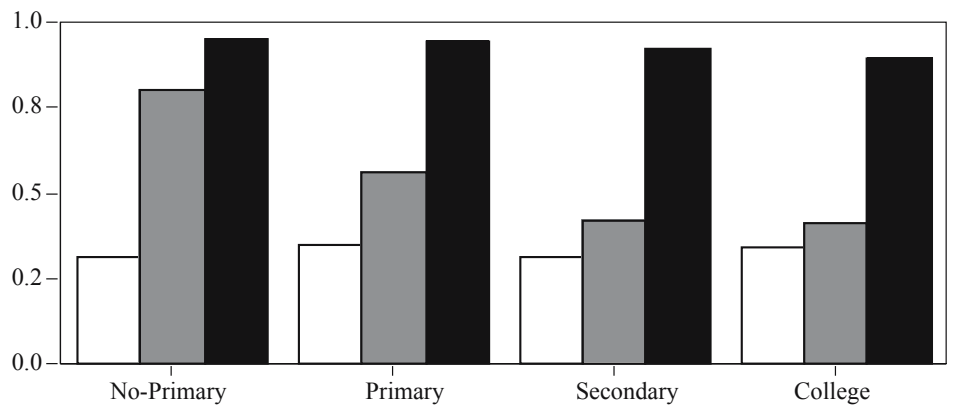

Panel 3: Sources of Income (\%)

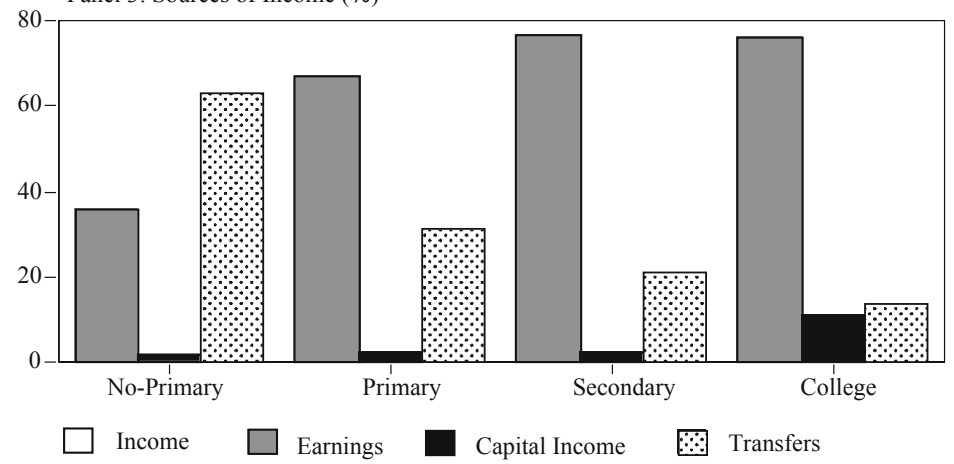

Fig. 7 Spanish household partitioned by education. Panel 1 Averages (1997 €), Panel 2 Gini indexes, Panel 3 Sources of income (\%). Source: Spanish Survey of the 1998 European Community Household Panel

It turns out that primary education households are the most numerous, they make up 51.5\% of the Spanish Europanel sample; secondary education households come next with $18.9 \%$; and both the no-primary and the college groups come next with approximately $15 \%$ of the sample each. The average income, 
earnings, capital income, and transfers of the education groups, are depicted in Panel 1 of Fig. 7. This figure unambiguously shows that there is a close association between education level and the economic performance of households. Specifically, the average income of college and secondary and primary education households are, respectively, 3.3, 2.0, and 1.5 times larger than the income of no-primary education households. Both earnings and capital income display a similar pattern, and the only exception is transfers. No-primary education households are the largest recipients of transfers followed by households who have only completed their primary education.

As Panel 2 of Fig. 7 illustrates, the concentrations of income and capital income are similar across education levels. This is not the case with earnings, which are most unequally distributed amongst the no-primary education households.

In Panel 3 of Fig. 7, we represent the income sources of the education groups. With the exception of the no-primary education group, that obtains $62.8 \%$ of its income from transfers, the remaining three education groups obtain most of their income from labor sources. We also find that college households obtain a significant share of their income from capital sources $(10.8 \%)$, and that the shares of income accounted for by transfers are clearly decreasing in the education groups. Finally, we find that the average household size is largest for college households (3.6 people), and that it is smallest for no-primary education households (2.7 people). However, the differences in household size across the three education groups are relatively small.

\section{Marital status and inequality}

To document the relationship between marital status and inequality, we partition the 1998 Spanish Europanel sample into married households and single households with and without dependents according to the marital status of the household heads. We also subdivide these last two groups according to the sex of the household heads. We refer to these groups as the "marital status partition". In Table 12 we report the averages for income, earnings, capital income, and transfers; the Gini indexes of the first three variables; the shares of income obtained from various sources; the number of people per household; and the relative group sizes for these marital status groups, and for the entire sample. In Panel 1 of Fig. 8, we represent the average income, earnings, capital income, and transfers of the marital groups. In Panel 2 of Fig. 8, we represent the Gini indexes of income, earnings, and capital income, and in Panel 3 of Fig. 8, we represent the income sources of the marital status groups.

First we compare married and single households. Married households are the largest group (66.8\% of the sample), single households without dependents come next $(29.6 \%)$, and the number of single households with dependents is very small (3.6\% of the sample). We find that married households make substantially higher income, earnings, and capital income than their single counterparts. However, this is not the case if we divide the income of married households by two, which is an admittedly crude way to account for double-income households. 
Table 12 Spanish households partitioned by marital status

\begin{tabular}{|c|c|c|c|c|c|c|c|c|c|c|c|c|}
\hline & \multicolumn{4}{|c|}{ Averages (1997 euros) } & \multicolumn{3}{|c|}{ Gini indexes } & \multicolumn{3}{|c|}{ Sources $(\%)$} & \multirow[t]{2}{*}{$S^{\mathrm{e}}$} & \multirow[t]{2}{*}{$\mathrm{H}^{\mathrm{f}}$} \\
\hline & $\overline{E^{\mathrm{a}}}$ & $I^{\mathrm{b}}$ & $K^{\mathrm{c}}$ & $Z^{\mathrm{d}}$ & $\bar{E}$ & $I$ & $K$ & $\bar{E}$ & $K$ & $Z$ & & \\
\hline Married & 587 & 13,174 & 921 & 1 & 38 & 0.52 & 0.95 & 74.9 & 5.2 & 9.9 & 3.6 & 66.8 \\
\hline Singles $w / o$ & 13,078 & 6,430 & 388 & 6,260 & 0.40 & 0.67 & 0.93 & 49.2 & 2.9 & 47.9 & 2.1 & 29.6 \\
\hline Singles w & 14,459 & 10,816 & 165 & 3,478 & 0.32 & 0.46 & 0.98 & 74.8 & 1.1 & 24.1 & 4.8 & 3.6 \\
\hline Single males w/o & 15,828 & 8,456 & 470 & 6,902 & 0.36 & 0.57 & 0.91 & 53.4 & 2.9 & 43.6 & 2.5 & 12.6 \\
\hline Single females w/o & 11,050 & 4,935 & 327 & 5,787 & 0.41 & 0.74 & 0.93 & 44.7 & 3.0 & 52.4 & 1.8 & 17.0 \\
\hline Single males w & 17,060 & 14,273 & 52 & 2,734 & 0.22 & 0.29 & 0.96 & 83.7 & 0.3 & 16.0 & 5.8 & 1.9 \\
\hline Single females w & 11,468 & 6,840 & 295 & 4,333 & 0.37 & 0.60 & 0.97 & 59.6 & 2.6 & 37.8 & 3.5 & 1.7 \\
\hline Total & 16,140 & 11,094 & 736 & 4,311 & 0.39 & 0.57 & 0.95 & 68.7 & 4.6 & 26.7 & 3.2 & 100 \\
\hline
\end{tabular}

Source: Spanish Survey of the 1998 European Community Household Panel

${ }^{\mathrm{a}}$ Income

${ }^{\mathrm{b}}$ Earnings

${ }^{\mathrm{c}}$ Capital income

dransfers

e Average number of persons per household

${ }^{f}$ Percentage number of households per age group

When we compare singles with and without dependents, we find that singles with dependents are somewhat better off than singles without dependents. We also find that while singles with dependents obtain a significantly larger share of their income from labor, singles without dependents receive a larger amount of transfers. Specifically, the average income of singles with dependents is $10.5 \%$ larger than that of singles without dependents, their average earnings are $68.2 \%$ larger, and their average transfers are $44.4 \%$ smaller. The significant number of retired widows in the sample $(8.3 \%)$ justifies these results in part.

We also find that earnings are most unequally distributed amongst single households without dependents. In contrast, the concentrations of both income and capital income are fairly similar across the three main marital status groups. Finally, as far as the sources of income are concerned, we find that the share of income accounted for by earnings is very similar for married households and for those headed by singles with dependents. As we have already mentioned, this share is significantly smaller for households headed by singles without dependents, and the opposite happens in the case of transfers.

Next we consider the partition of single households according to the sex of the household heads. No surprisingly, in the 1998 Spanish Europanel sample, the households headed by single females outnumber those headed by single males. Specifically, their sample shares are $18.7 \%$ and $14.5 \%$, respectively. This difference is consistent with the fact that females live longer than males.

We find that, on average, single females both with and without dependents are significantly worse off than their male counterparts. Specifically, the average income earned by households headed by single males without dependents is $43.3 \%$ larger than that earned by their female counterparts, and the average income earned by males with dependents is $48.8 \%$ larger. Only as transfer 

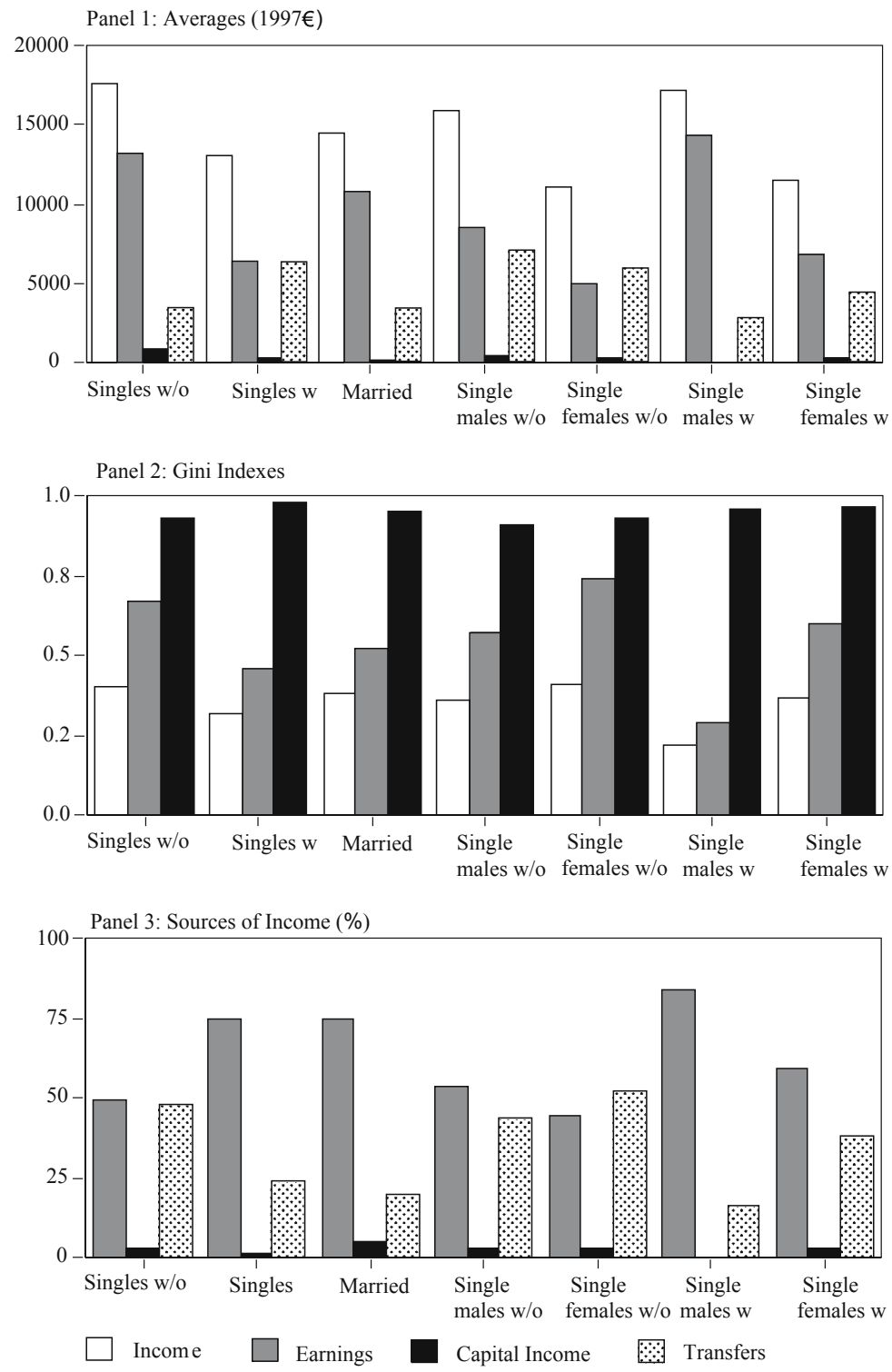

Fig. 8 Spanish household partitioned by marital status. Panel 1 Averages (1997 €), Panel 2 Gini indexes, Panel 3 Sources of income (\%). Source: Spanish Survey of the 1998 European Community Household Panel 
recipients single females with dependents fare better off than their male counterparts (their average transfers are 58\% larger).

As far as the economic inequality amongst single households with dependents is concerned, we find that all three variables are more unequally distributed amongst households headed by females than amongst those headed by males (see Panel 2 of Fig. 8).

Finally, as Panel 3 of Fig. 8 illustrates, households headed by single females, both with and without dependents, earn smaller shares of their income from earnings and larger shares from transfers than the corresponding groups headed by single males.

\section{Income mobility}

People move up and down the economic scale; they do not stay in the same income groups forever. Aging is perhaps the main cause for this type of economic mobility, but it is certainly not the only one. Mobility is also affected by the results of business projects and other ventures that can bring about significant changes in earnings to lucky or unlucky entrepreneurs. There can also be some other radical expressions of good luck (such as gambling), or bad luck (such as accidents). Furthermore, other changes in economic groups are a consequence of the conscious effort of households to smooth their consumption over time. Whatever its cause, economic mobility makes inequality an essentially dynamic phenomenon.

To measure economic mobility, we use data from the 1994 and 1998 waves of the Europanel. We use these data to construct Table 13 where we report the transition matrices for the 1994 income quintiles. For example, the entry in the first row and the first column of Table 13 reports that $61.3 \%$ of the households in the bottom income quintile in 1994 were also in the bottom income quintile in 1998 .

To summarize this mobility information, in Table 14 we report the fractions of the households of the quintiles of the income distribution that have moved to a different quintile during the four years lapsed between 1994 and 1998. We

Table 13 Income mobility of Spanish households (1994-1998)

\begin{tabular}{lrrrrr}
\hline From 1994 & To 1998 & \multicolumn{3}{c}{} \\
\cline { 2 - 6 } & $0-20$ & $20-40$ & $40-60$ & $60-80$ & $80-100$ \\
\hline $0-20$ & 61.3 & 20.9 & 8.1 & 7.0 & 2.7 \\
$20-40$ & 17.7 & 44.0 & 23.7 & 11.0 & 3.6 \\
$40-60$ & 9.9 & 19.4 & 40.4 & 24.1 & 6.2 \\
$60-80$ & 6.4 & 9.6 & 22.2 & 41.4 & 20.4 \\
$80-100$ & 2.9 & 6.3 & 8.1 & 23.4 & 59.3 \\
\hline
\end{tabular}

Source: 1994 and 1998 Spanish Surveys of the European Community Household Panel 
Table 14 Summary income mobility statistics for Spanish households

\begin{tabular}{lrrrrrr}
\hline & $r^{\mathrm{a}}$ & 1st Q & 2nd Q & 3rd Q & 4th Q & 5th Q \\
\hline All & 0.357 & 38.7 & 56.0 & 59.6 & 58.6 & 40.7 \\
Non-retired $^{\mathrm{c}}$ & 0.385 & 45.5 & 62.5 & 61.7 & 59.9 & 38.9 \\
Age 25-45 $^{\mathrm{d}}$ & 0.322 & 29.6 & 50.9 & 59.0 & 59.6 & 39.5 \\
\hline
\end{tabular}

Source: Spanish Survey of the 1998 European Community Household Panel

${ }^{a}$ This column reports one minus the second highest eigenvalues of the corresponding mobility matrices

${ }^{b}$ The last five columns of this table report the fractions of the households of each quintile that have moved to a different quintile between 1994 and 1998

${ }^{\mathrm{c}}$ This row reports the mobility statistics of earnings for households whose head had not retired in 1998

${ }^{d}$ This row reports the mobility statistics of earnings for households whose heads were between 25 and 45 years old in 1994

call these fractions the mobility statistics. ${ }^{9}$ In Fig. 9 we represent these mobility statistics for the income quintiles.

For some purposes, the mobility statistics reported in the last five columns of Table 14 might still contain too much information, and it might be useful to have a simpler, one-dimensional summary statistic for each variable. One such statistic is a simple arithmetic transformation of the second-highest eigenvalue of the mobility matrix. ${ }^{10}$ The closer this eigenvalue is to 1 , the more persistent is the variable under study. Consequently, the closer one minus the second-highest eigenvalue is to 1 , the more mobile is the variable under study. We report this statistic in the first column of Table 14.

In the first row of Table 14 we report the summary mobility statistics for all the sample households. To evaluate the roles played by age and employment status in shaping economic mobility, we also report the summary statistics for the households whose head had not retired in 1998 and for the households whose head was between 25 and 45 years old in 1994.

As Fig. 9 illustrates, we find that in all three cases the income mobility statistics are clearly hump-shaped. In general, the bottom and the top quintiles should be the least mobile, since the households in those quintiles can only move either up or down the economic scale, while the households in the middle quintiles can move both up and down. In the 1994-1998 period this was indeed the case and the households in the three middle quintiles are clearly the most mobile.

If we consider the second-highest eigenvalues of the mobility matrices, we find that retired households are less mobile than average, and that the households in the $25-45$ age cohort are the least mobile. This is because these

\footnotetext{
9 Note that the shares reported in each of the rows of Table 14 are one minus the shares reported in the diagonal of the mobility matrix of Table 13 .

10 Note that the highest eigenvalue of probability transition matrices is always 1 .
} 


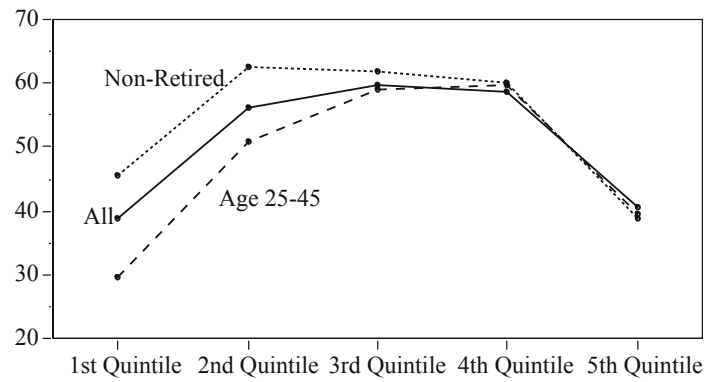

Fig. 9 The Mobility of the income quintiles (1994-1998). Source: Spanish Survey of the 1998 European Community Household Panel

households were relatively young in 1994 and 4 years is not long enough for people to experience large changes in their economic status.

\section{International comparisons}

As we have already mentioned, one of the purposes of the Europanel was to obtain "comparable information across the European Union member states". In this section we describe briefly how some of the income, earnings and capital income inequality statistics of Germany, France, the United Kingdom, Italy, Portugal, Sweden, compare to those of Spain. We also construct the Lorenz curve of income of these eight European countries put together and we call the resulting aggregate EU7. ${ }^{11}$ Finally, for completeness sake, and even though the survey methodology is very different, we also report inequality data for the US economy which we have computed using the 1998 Wave of the US Survey of Consumer Finances.

In Table 15, we report the Gini indexes and selected points of the Lorenz curves of the income distributions of the countries listed above, of the EU7 and of the United States. When comparing these measures of inequality, we must keep in mind that these countries have very different population sizes, and that the differences in sampling errors across countries may be quite large. In 2002, the US population was 288.5 million. Amongst the European countries, Germany was the largest with a population of 82.0 million. France and the United Kingdom come next, both with a population of 59.7 million people. They are followed by Italy with 57.4 million and Spain with 39.9 million people. Finally, Portugal and Sweden, with 10.0 and 8.8 million people, are the two smallest countries considered.

The comparisons between the US and the European countries must be qualified further because of the different methodologies used to design and conduct their surveys. As we have already mentioned, the US data are taken from the

11 To construct the EU7 sample we have used the purchasing power parity excahnge rates provided by the Europanel. 
1998 Survey of Consumer Finances (SCF). Unlike the Europanel, the SCF is not a panel. Instead, $70 \%$ of the SCF sample is replaced every year. In addition, one of the main concerns of the SCF is to offer an accurate representation of the top tail of the wealth distribution. Consequently, unlike the Europanel, the SCF oversamples the rich and minimizes top coding. This feature of the SCF is bound to result in more measured inequality in the US than in the European countries. For details on the SCF, see Budría et al. (2002).

Probably the most striking feature of Table 15 is that income is indeed more unequally distributed in the US than in every European country considered here. The share of income earned by the households in the bottom quintile of the U.S. income distribution (2.4\%) is almost half of the $4.4 \%$ earned by the poorest of the European poor, who happen to be the Portuguese, and exactly one-third of the $7.2 \%$ earned by the income poor Swedes, who are the richest amongst the European poor. When we consider the top tails of the distribution, we find that the rich households in the US sample are significantly richer than their European counterparts. Specifically, the households in the top quintile of the US income distribution earn $58.0 \%$ of the total sample income, which is 12.1 percentage points more than the share earned by the richest top quintile amongst the European countries (Portugal again) and 19.8 percentage points more than the poorest European top quintile (Sweden again). The differences in the top percentile are even more striking, but they must be interpreted with care because a large share of these differences is due to the overrepresentation of the US rich in the SCF sample.

Another noticeable feature of Table 15 is that the differences in income inequality amongst the European countries considered here are not very large. According to the Gini indexes, income is most unequally distributed in Portugal (0.41) and is least unequally distributed in Sweden (0.32). Spain, with an income Gini index of 0.39 ranks immediately after Portugal and it is tied with the UK The shares of income earned by the different groups are also quite similar in the various European countries. Specifically, the maximum differences are 2.8 percentage points amongst the bottom quintile and 7.7 percentage points amongst the top quintile.

In Table 16 we report the Gini indexes, the coefficients of variation and the locations of the means of the income, earnings and capital income distributions of the eight countries listed above. In brackets besides each statistic we report the ranking of each country according to the statistic reported in each column.

Both the Gini indexes and the coefficients of variation confirm that, in every single country, capital income is the most unequally distributed of the three variables, that earnings ranks second, and that income is the most equally distributed of the three. Amongst the European countries, the range of the capital income Gini indexes (from 0.80 in France to 0.97 in Portugal) is significantly larger than the ranges of the Gini indexes of either earnings (from 0.53 in Portugal to 0.60 in the UK) or income (from 0.32 in Sweden to 0.41 in Portugal). This same property of the data is confirmed by the coefficients of variation. Notice also the curious case of Portugal: while its labor earnings are the most equally distributed amongst the European countries, its capital 
Table 15 International comparisons: the income distributions (1998)

\begin{tabular}{|c|c|c|c|c|c|c|c|c|c|c|c|c|}
\hline & \multirow{2}{*}{ Gini } & \multicolumn{3}{|c|}{ The poor } & \multicolumn{5}{|c|}{ Quintiles } & \multicolumn{3}{|c|}{ The rich } \\
\hline & & 1 & $1-5$ & $\overline{5-10}$ & $1 \mathrm{st}$ & 2 nd & $3 \mathrm{rd}$ & 4 th & $\overline{5 \text { th }}$ & $10-5$ & $5-1$ & 1 \\
\hline Spain & 0.39 & 0.0 & 0.6 & 1.4 & 5.4 & 10.7 & 15.9 & 23.3 & 44.6 & 10.7 & 11.1 & 6.4 \\
\hline Germany & 0.34 & 0.0 & 0.6 & 1.4 & 6.2 & 12.3 & 17.7 & 24.2 & 39.6 & 9.8 & 9.8 & 4.1 \\
\hline France & 0.35 & 0.0 & 0.7 & 1.5 & 6.3 & 11.8 & 17.1 & 23.7 & 41.0 & 9.9 & 10.4 & 4.9 \\
\hline UK & 0.39 & 0.0 & 0.6 & 1.3 & 5.4 & 10.4 & 16.0 & 24.4 & 43.7 & 10.5 & 11.1 & 5.4 \\
\hline Italy & 0.35 & 0.0 & 0.7 & 1.4 & 6.1 & 11.9 & 17.1 & 24.3 & 40.7 & 9.9 & 10.4 & 4.3 \\
\hline Portugal & 0.41 & 0.0 & 0.5 & 1.0 & 4.4 & 10.4 & 16.2 & 23.2 & 45.9 & 11.3 & 12.2 & 5.6 \\
\hline Sweden & 0.32 & 0.5 & 0.8 & 1.8 & 7.2 & 12.3 & 17.5 & 24.8 & 38.2 & 9.2 & 9.1 & 4.2 \\
\hline EU7 & 0.37 & 0.0 & 0.6 & 1.3 & 5.7 & 11.3 & 16.7 & 24.0 & 42.3 & 10.3 & 10.9 & 4.9 \\
\hline USA & 0.55 & -0.1 & 0.1 & 0.5 & 2.4 & 7.2 & 12.5 & 20.0 & 58.0 & 10.3 & 15.3 & 17.5 \\
\hline
\end{tabular}

Sources: 1998 European Community Household Panel and 1998 Survey of Consumer Finances (US)

Table 16 International comparisons: concentration and skewness statistics (1998)

\begin{tabular}{lccc}
\hline & Income & Earnings & Capital income \\
\hline Gini indexes & & & \\
Spain & $0.39(5)$ & $0.57(5)$ & $0.95(7)$ \\
Germany & $0.34(2)$ & $0.56(3)$ & $0.83(3)$ \\
France & $0.35(3)$ & $0.57(5)$ & $0.80(1)$ \\
UK & $0.39(5)$ & $0.60(7)$ & $0.84(4)$ \\
Italy & $0.35(3)$ & $0.54(2)$ & $0.93(6)$ \\
Portugal & $0.41(7)$ & $0.53(1)$ & $0.97(8)$ \\
Sweden & $0.32(1)$ & $0.56(3)$ & $0.84(4)$ \\
USA & $0.55(8)$ & $0.61(8)$ & $0.80(1)^{\mathrm{a}}$ \\
Coefficients of variation & & & \\
Spain & $0.81(5)$ & $1.13(5)$ & $6.12(6)$ \\
Germany & $0.66(2)$ & $1.08(3)$ & $4.23(4)$ \\
France & $0.78(4)$ & $1.24(7)$ & $2.88(2)$ \\
UK & $0.81(5)$ & $1.23(6)$ & $2.85(1)$ \\
Italy & $0.68(3)$ & $1.04(1)$ & $4.56(5)$ \\
Portugal & $0.84(7)$ & $1.07(2)$ & $7.96(8)$ \\
Sweden & $0.63(1)$ & $1.08(3)$ & $3.94(3)$ \\
USA & $3.57(8)$ & $2.65(8)$ & $6.53(7)^{\mathrm{a}}$ \\
Locations of the means (percentiles) & & & \\
Spain & $62(6)$ & $58(4)$ & $91(7)$ \\
Germany & $58(1)$ & $54(1)$ & $82(4)$ \\
France & $60(4)$ & $58(4)$ & $80(1)$ \\
UK & $61(5)$ & $59(6)$ & $83(5)$ \\
Italy & $59(3)$ & $54(1)$ & $87(6)$ \\
Portugal & $63(7)$ & $59(6)$ & $93(8)$ \\
Sweden & $58(1)$ & $55(3)$ & $80(1)$ \\
USA & $71(8)$ & $65(8)$ & $81(3)^{\mathrm{a}}$ \\
\hline Sources: & &
\end{tabular}

Sources: 1998 European Community Household Panels and 1998 Survey of consumer Finances (US)

a The data reported for the US in the Capital Income column corresponds to household wealth (see Budría et al. 2002) 
income is the most unequally distributed. Finally, both the Gini indexes and the coefficients of variation confirm that economic inequality is above average in Spain.

As far as the skewness of the distributions is concerned, the last panel of Table 16 establishes that all three distributions are skewed to the right in every one of the countries considered, and that the capital income distribution is significantly more skewed to the right than the distributions of the other two variables. Once again, the three distributions are more skewed to the right in the US than in the European countries, and the skewness of the Spanish distributions is towards the high end of each range.

\section{Concluding comments}

Years ago Finn Kydland and Edward C. Prescott argued that "the reporting of facts - without assuming that the data are generated by some probability model-is an important scientific activity" and that economics should not be an exception. ${ }^{12}$ This article is an detailed report on some of the inequality facts of the Spanish economy. These facts confirm that inequality is a complex and multidimensional subject, and that most of these dimensions can be described using several statistics. Recent theoretical work (see for instance Huggett 1996; Krusell and Smith 1998; Castañeda et al. 2003; De Nardi 2004), has been successful in accounting for a small subset of the statistics for the U.S. economy. We think that it is high time that similar work was done for the European economies, and more specifically, for Spain. This article wants to be a first step in that direction.

Acknowledgements We gratefully acknowledge the valuable comments and suggestions of an anonymous referee. Budría thanks the financial support of the European Commission, EDWIN project HPSE-CT-2002-00108. Díaz-Giménez thanks the Fundación de Estudios de Economía Aplicada (FEDEA), the Spanish Ministerio de Ciencia y Tecnología (Grant SEC2002-004318) and the Fundación Areces for their financial support.

\section{Appendix: Weighting, imputation, scaling and sample units}

In this Appendix we provide a brief discussion of some of the technical issues related to the representativity of the Spanish panel. For a more detailed discussion of these issues, the interested reader should consult Eurostat (2000a,b), Peracchi (2002) and Nicoletti and Peracchi (2004).

\section{Weighting}

Every statistic reported in this paper has been calculated using the sample weights provided by the Europanel. The purpose of these weights is to make

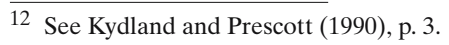


the sample representative of the Spanish population. The weights are designed to compensate for the unequal selection probabilities and response rates of the various household classes. ${ }^{13}$ In each wave of the panel, these weights are adjusted to take into account changes in the population and attrition rates. Naturally, the quality of these weights is crucial for the representativity of the sample. See Peracchi (2002) and Nicoletti and Peracchi (2004) for a detailed discussion of this issue.

From 1994 to 1998, the attrition rate in the Spanish Survey of the Europanel was $32.8 \%$. A way to find out whether this loss of observations has affected by much the representativity of the sample, and to quantify the role played by the weights is to compare the weighted and unweighted distributions of 1994 and $1998{ }^{14}$ This we do in Table 17. We find that, with the only exception of the top percentile, the Lorenz curves of the distributions and their Gini indexes are very similar for the two years considered and for the two measures of income considered.

If we believe that the changes in the true Spanish income distribution during the rather stable period between 1994 and 1998 should have been small, we can interpret these results to mean that the loss of representativity of the Spanish sample due to attrition has been small, at least as far as the Lorenz curve of the income distribution is concerned. This result also makes us think that the quality of the Spanish sample weights is reasonably good.

\section{Imputation}

Sometimes households fail to answer some of the survey questions. In these cases, the Europanel uses a statistical procedure to impute the missing values. ${ }^{15}$ For each household and for each variable the Europanel reports the amount of that variable that has been imputed. The purpose of the imputation procedure is to compensate for the loss of observations due to item nonresponse and, consequently, to reduce the non-response bias. However, like all other survey correction procedures, if the imputation is incorrect, it can back-fire and it may end up increasing the sizes of the sampling errors instead of reducing them.

To get a quantitative feeling for the possible imputation bias, in Table 18 we report the shares of non-respondents and of the amounts imputed to the various components of income in the 1998 Spanish Survey of the Europanel. We find that $11.6 \%$ of the households did not respond to some of the income questions. Moreover, non-response is much more frequent in capital income

\footnotetext{
13 The Europanel groups the Spanish households into classes according to their geographical location, the number of economically active persons in the household, the size of the household and the type of tenure (whether owner-occupied, rented, or rent-free accommodation), among other variables. For further details about this issue, see Eurostat (2000a).

14 Recall that 1994 was the first year of the Spanish survey. Consequently, that year there was no attrition.

15 See Eurostat (2000b) for a detailed description and discussion of the imputation procedure.
} 
Table 17 The Spanish income distributions (percentage shares of the sample totals)

\begin{tabular}{|c|c|c|c|c|c|c|c|c|c|c|c|c|}
\hline & \multirow{2}{*}{ Gini } & \multicolumn{3}{|c|}{ The poor } & \multicolumn{5}{|c|}{ Quintiles } & \multicolumn{3}{|c|}{ The rich } \\
\hline & & 1 & $1-5$ & $\overline{5-10}$ & $\overline{1 \mathrm{st}}$ & 2 nd & $3 \mathrm{rd}$ & 4th & $\overline{5 \text { th }}$ & $\overline{10-5}$ & $5-1$ & 1 \\
\hline \multicolumn{13}{|c|}{ The Spanish income distributions in 1994} \\
\hline Unweighted & 0.37 & 0.0 & 0.7 & 1.4 & 5.8 & 11.7 & 16.8 & 24.3 & 41.5 & 10.3 & 10.4 & 4.3 \\
\hline Weighted & 0.38 & 0.0 & 0.7 & 1.4 & 5.6 & 11.0 & 16.2 & 23.5 & 43.7 & 10.7 & 11.4 & 5.1 \\
\hline \multicolumn{13}{|c|}{ The Spanish income distribution in 1998} \\
\hline Unweighted & 0.37 & 0.0 & 0.7 & 1.5 & 5.8 & 11.3 & 16.6 & 23.7 & 42.6 & 10.5 & 11.0 & 4.8 \\
\hline Weighted & 0.39 & 0.0 & 0.6 & 1.4 & 5.4 & 10.7 & 15.9 & 23.3 & 44.6 & 10.7 & 11.1 & 6.4 \\
\hline
\end{tabular}

Source: 1994 and 1998 Spanish Surveys of the European Community Household Panel

Table 18 Imputation in the Europanel (percentage shares)

\begin{tabular}{lrr}
\hline & Non-response & Amount imputed \\
\hline Income & 11.6 & 4.9 \\
Earnings & 1.4 & 0.8 \\
$\quad$ Wage and salary earnings & 8.2 & 6.8 \\
$\quad$ Self-employment income & 11.8 & 3.4 \\
Capital income & 0 & 0 \\
$\quad$ Capital income & 0 & \\
Property rental income & & \\
\hline
\end{tabular}

Source: 1998 Spanish Survey of the European Community Household Panel

and in self-employment income than in wage and salary earnings. We also find that the share of income imputed is less than $5 \%$ of the total, that the largest amount imputed corresponds to self-employment income (6.8\%), and that the amount imputed to earnings is tiny $(0.8 \%)$.

Nicoletti and Peracchi (2004) have explored the overall impact of imputation in the Europanel in great detail. Using data from all the Europanel countries, they find that salary earnings tend to be underestimated for item non-respondents. However, since the share of households with imputed salary earnings is small, the overall imputation bias for earnings should also be small. On the other hand, item nonresponse for income from self-employment is high, but Nicholetti and Peracchi find no evidence of bias in this variable.

Overall, our results suggest that the size of the imputation bias in the 1998 Spanish Survey of the Europanel is small. Specifically, the imputation indexes reported in Table 18 are significantly smaller than those reported by Peracchi (2002) for previous waves of the survey and for all the Europanel countries. This leads us to believe that, overall, the inequality data reported in this paper are reasonably accurate.

Scaling and sample units

As we have mentioned above, the main purpose of this article is to provide a set of stylized facts that measure and describe economic inequality in Spain. 
Table 19 The Spanish income distributions: households, scaled households and individuals

\begin{tabular}{|c|c|c|c|c|c|c|c|c|c|c|c|c|}
\hline & \multirow[t]{2}{*}{ Gini } & \multicolumn{3}{|c|}{ The poor } & \multicolumn{5}{|c|}{ Quintiles } & \multicolumn{3}{|c|}{ The rich } \\
\hline & & 1 & $1-5$ & $\overline{5-10}$ & $\overline{1 s t}$ & 2nd & $3 \mathrm{rd}$ & 4th & $\overline{5 \text { th }}$ & $\overline{10-5}$ & $5-1$ & $\overline{1}$ \\
\hline \multicolumn{13}{|c|}{ Distributions of households } \\
\hline Unscaled & 0.39 & 0.0 & 0.6 & 1.4 & 5.4 & 10.7 & 15.9 & 23.3 & 44.6 & 10.7 & 11.1 & 6.4 \\
\hline Size scaling & 0.36 & 0.0 & 0.6 & 1.4 & 6.2 & 12.0 & 16.6 & 22.5 & 42.7 & 10.3 & 11.5 & 5.2 \\
\hline OECD scaling & 0.35 & 0.0 & 0.6 & 1.5 & 6.6 & 12.4 & 16.3 & 22.8 & 41.8 & 10.2 & 10.9 & 4.9 \\
\hline \multicolumn{13}{|c|}{ Distributions of individuals } \\
\hline Ages 26-55 & 0.54 & 0 & 0 & 0 & 0 & 3.7 & 16.6 & 27.6 & 52.2 & 12.5 & 13.6 & 6.3 \\
\hline Ages 16-65 & 0.61 & 0 & 0 & 0 & 0 & 0.6 & 12.7 & 27.9 & 58.8 & 14.2 & 15.7 & 7.4 \\
\hline
\end{tabular}

Source: 1998 Spanish Survey of the European Community Household Panel

Naturally choosing either households or individuals as the sample units has large consequences for the measurement of inequality. Moreover, when we choose households as the sample units, whether or not to scale the household variables is potentially important. The Europanel reports data both on households and on the individuals that make up these households. In the body of the paper we have focused exclusively on household data because we consider the household to be the basic economic decision making unit.

To give the reader a quantitative feel for the role played by the choices of sample units and scaling procedures, in the top rows of Table 19 we report the Gini indexes and selected points of the Lorenz curves of the income distributions that we obtain when we use unscaled household data as we do in the body of this article (first row), and when we scale the household data dividing by the household size (second row), or by the OECD equivalized household size (third row). ${ }^{16}$ Next, in the bottom rows of Table 19, we report the we report the Gini indexes and selected points of the Lorenz curves of the income distributions that we obtain when we use as sample units individuals in the 26-55 and in the in the 16-65 age cohorts.

We find that scaling makes very little difference when we use households as the sample units. This means that household size is very evenly distributed amongst the income groups. When we use unscaled household data, the Gini index of the income distribution (0.39) is somewhat higher than when we use scaled household data ( 0.36 and 0.35 ) but the increase in measured inequality due to scaling is small. Moreover, the differences between the Gini indexes obtained with the two scaling procedures are tiny.

On the other hand, if we use data on individuals, we find that there is a large increase in our measures of income inequality. When we consider the 26-55 age cohort, the Gini index of the income distribution jumps to 0.54 , and when we extend the sample to the 16-65 age cohort, the Gini index of the income distribution increases further to 0.61 .

\footnotetext{
16 The OECD equivalized household size, $E$ is defined as follows: let $A$ be the number of household members who are older than 14 , and let $S$ be the household size, then $E=1+0.7 \times(A-1)+0.5(S-A)$.
} 


\section{References}

Auerbach AJ, Kotlikoff LJ (1987) Dynamic fiscal policy. Cambridge University Press, New York

Budría S, Díaz-Giménez J, Quadrini V, Ríos-Rull J-V (2002) New facts on the distributions of earnings, income and wealth in the US". Federal Reserve Bank Minneapolis Q Rev 26:2-35

Castañeda A, Díaz-Giménez J, Ríos-Rull J-V (2003) Accounting for the US earnings and wealth inequality. J Polit Econ 111:818-857

De Nardi M (2004) Wealth inequality and intergenerational links. Rev Econ Stud 71:743-768

Eurostat (1996) The European community household panel: survey methodology and implementation. Vol 1, Office for Official Publications of the European Communities, Luxembourg

Eurostat (2000a) Construction of the weights in the European Community Household Panel. PAN $165 / 00$, Eurostat, Luxembourg

Eurostat (2000b) Imputation of income in the European Community Household Panel. PAN $164 / 00$, Eurostat, Luxembourg

Fullerton D, Rogers DL (1993) Who bears the lifetime tax burden. The Brookings Institution, Washington

Huggett M (1996) Wealth distribution in life-cycle economies. J Monetary Econ 38:469-494

Krusell P, Smith A (1998) Income and wealth heterogeneity in the macroeconomy. J Polit Econ 106:867-896

Kydland F, Prescott EC (1990) Business cycles: real facts and a monetary myth. Federal Reserve Bank Minneapolis Q Rev 14:3-18

Nicoletti C, Peracchi F (2004) The effects of income imputation on micro analyses: evidence from the European Community Household Panel. Institute for Social and Economic Research Working Paper 2004-19

Peracchi F (2002) The European Community Household Panel: a review. Empirical Econ 27:63-90

Ríos-Rull JV (1996) Life cycle economies and aggregate fluctuations. Rev Econ Stud 63(3)(215):465-490 